$8 / 4-15-97$ gs (1)

SAND97-8490 • UC-404

Unlimited Release

$M 97052550$

SAND- $97-8490$

Printed March 1997

\title{
Mechanical Properties and Energy Absorption Characteristics of a Polyurethane Foam
}

S. H. Goods, C. L. Neuschwanger, C. Henderson, D. M. Skala

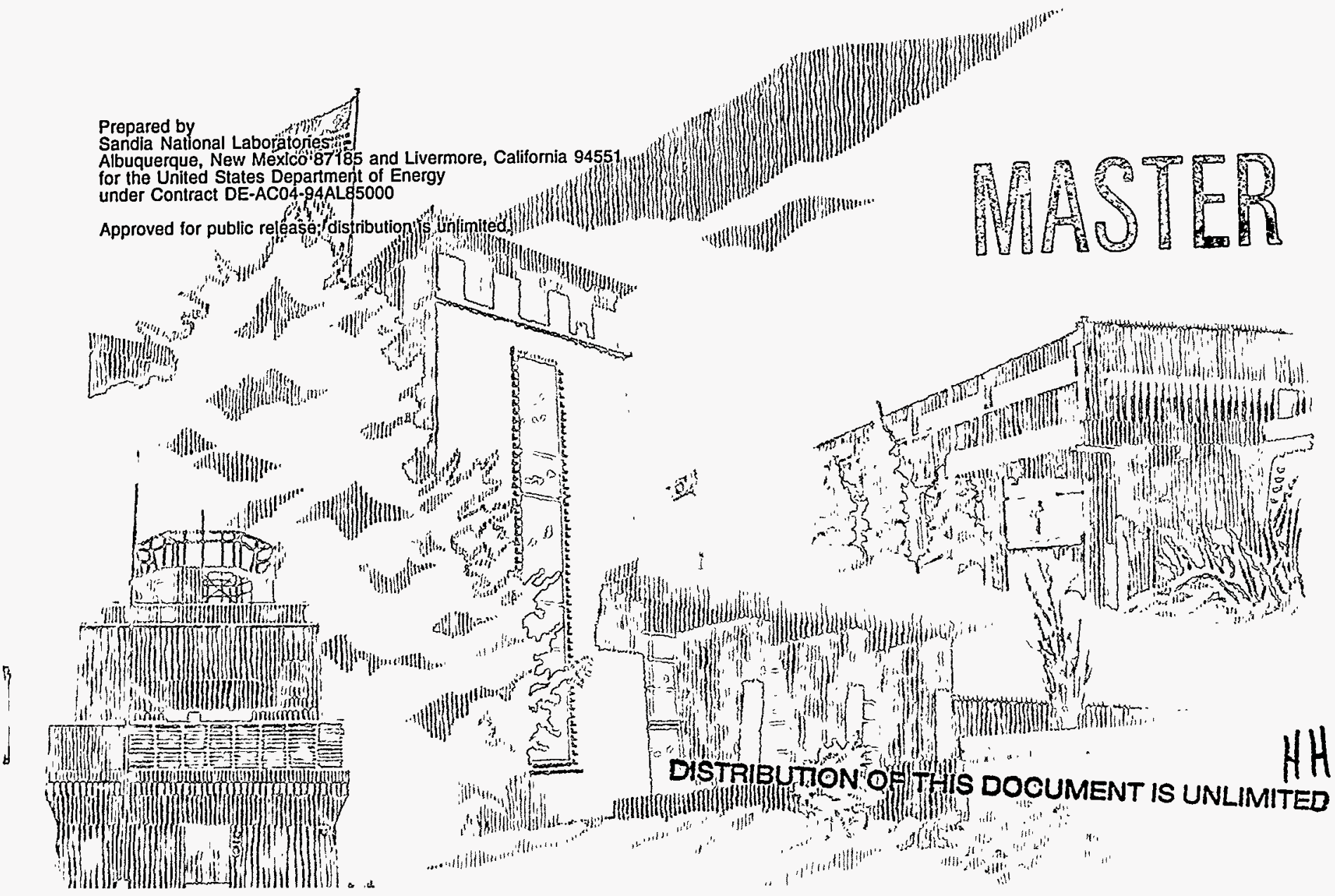




\section{DISCLAIMER}

This report was prepared as an account of work sponsored by an agency of the United States Government. Neither the United States Government nor any agency thereof, nor any of their employees, make any warranty, express or implied, or assumes any legal liability or responsibility for the accuracy, completeness, or usefulness of any information, apparatus, product, or process disclosed, or represents that its use would not infringe privately owned rights. Reference herein to any specific commercial product, process, or service by trade name, trademark, manufacturer, or otherwise does not necessarily constitute or imply its endorsement, recommendation, or favoring by the United States Government or any agency thereof. The views and opinions of authors expressed herein do not necessarily state or reflect those of the United States Government or any agency thereof. 


\section{DISCLAIMER}

\section{Portions of this document may be illegible in electronic image products. Images are produced from the best available original document.}


SAND 97-8490

UC-404

Unlimited Release

Printed March 1997

\title{
MECHANICAL PROPERTIES AND ENERGY ABSORPTION CHARACTERISTICS OF A POLYURETHANE FOAM
}

\author{
S. H. Goods \\ Materials Reliability Department \\ C. L. Neuschwanger, C. Henderson, and D. M. Skala \\ Polymer and Electrochemical Technologies Department \\ Sandia National Laboratories/California
}

\begin{abstract}
Tension, compression and impact properties of a polyurethane encapsulant foam have been measured as a function of foam density. Significant differences in the behavior of the foam were observed depending on the mode of testing. Over the range of densities examined, both the modulus and the elastic collapse stress of the foam exhibited power-law dependencies with respect to density. The power-law relationship for the modulus was the same for both tension and compression testing and is explained in terms of the elastic compliance of the cellular structure of the foam using a simple geometric model. Euler buckling is used to rationalize the density dependence of the collapse stress.

Neither tension nor compression testing yielded realistic measurements of energy absorption (toughness). In the former case, the energy absorption characteristics of the foam were severely limited due to the inherent lack of tensile ductility. In the latter case, the absence of a failure mechanism led to arbitrary measures of energy absorption that were not indicative of true material properties. Only impact testing revealed an intrinsic limitation in the toughness characteristics of the material with respect to foam density. The results suggest that dynamic testing should be used when assessing the shock mitigating qualities of a foam.
\end{abstract}




\section{ACKNOWLEDGMENT}

The authors wish to acknowledge the efforts of numerous colleagues for their support during the course of this study. In particular, we thank John Tan (8230) for the fabrication of much of the sample material, and Rafael Davalos (2254) and John Krafcik (8240) for their assistance in generating the schematic representations of the cell structures 


\section{CONTENTS}

\section{Page}

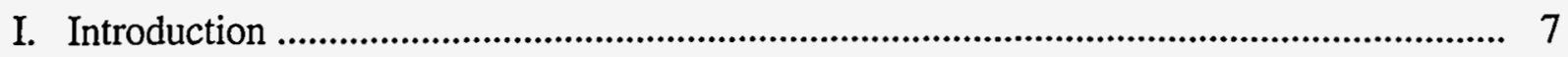

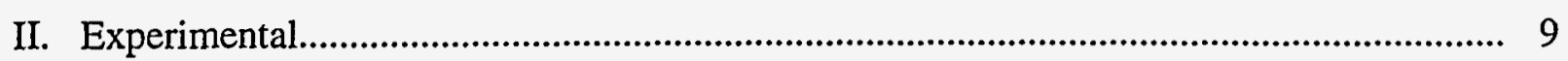

Formulation of CRETE Foam System................................................................. 9

Processing CRETE Foam System............................................................................ 10

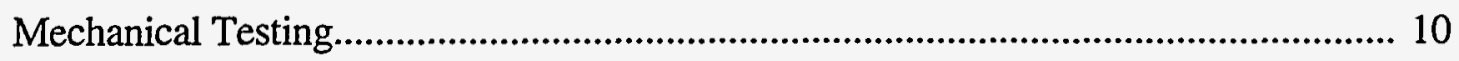

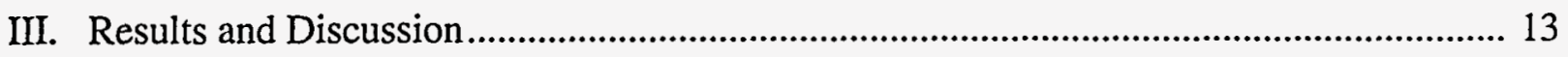

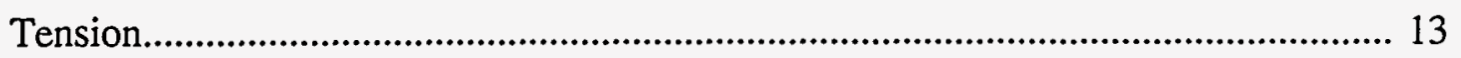

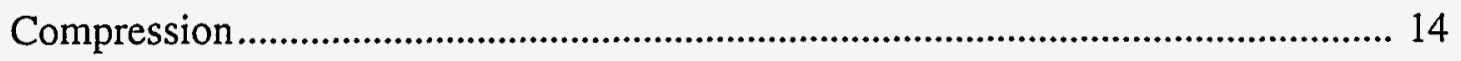

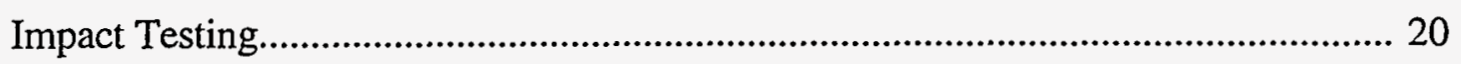

IV. Relationship Between the Structure of Foams and Mechanics of Deflection...................... 25

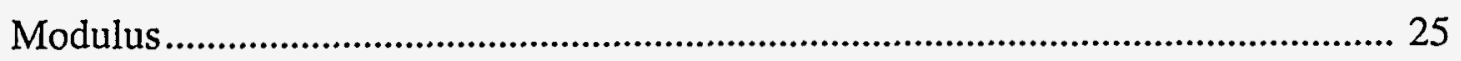

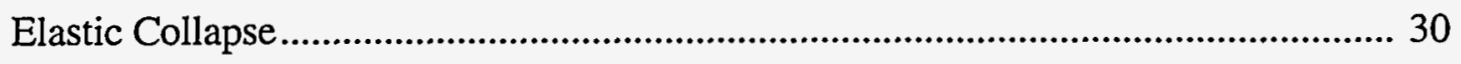

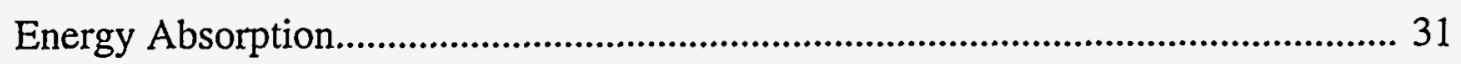

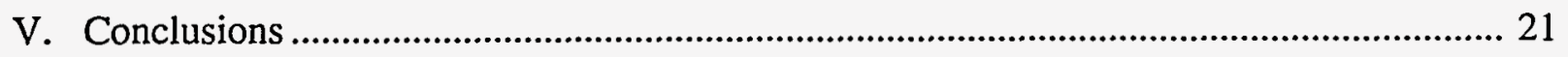

Energy Absorption Characteristics of the Foam System ............................................. 33

Structure Dependence of Modulus and Collapse Stress................................................ 33

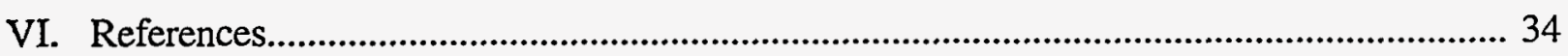

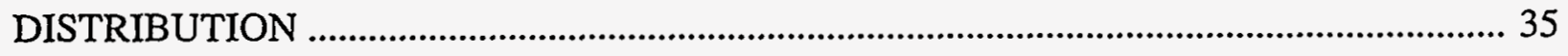




\section{ILLUSTRATIONS}

No.

Page

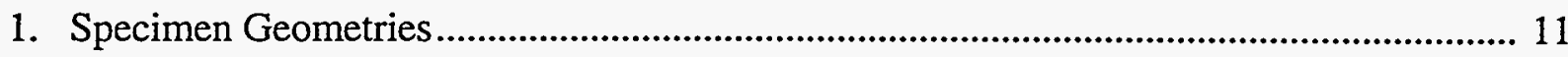

2. Energy Absorption or Toughness from Stress-Strain Curves..................................... 12

3. Comparison of Tensile Behavior Comparison for Five Tests........................................... 13

4. Modulus vs. Density (from Tension Testing) ............................................................... 14

5. Energy Absorption (from Tension Testing) ................................................................. 15

6. Compression Behavior of Foam Specimen ................................................................ 16

7. Comparison of Tensile and Compression Behavior ...................................................... 17

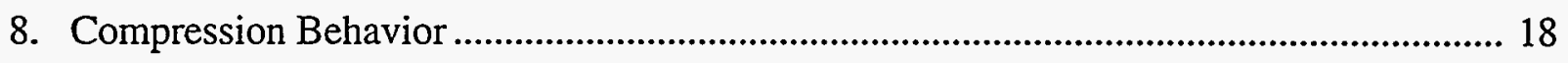

9. Modulus vs. Density (from Tension and Compression Testing)...................................... 18

10. Elastic Collapse Stress vs. Density ..................................................................... 19

11. Energy Absorption for Tension and Compression Tests................................................... 20

12. Strain Rate Effects on Compression Behavior............................................................... 21

13. Stress and Energy Absorption from Impact Testing .................................................... 22

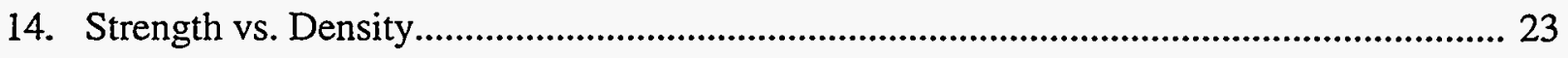

15. Energy Absorption vs. Density (from Impact Testing) ................................................... 24

16. Simplified Unit Cell for an Open Cell Foam ................................................................ 26

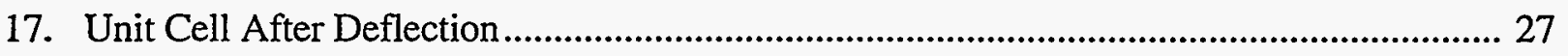

18. Unit Cell for a Closed Cell Foam................................................................................ 29

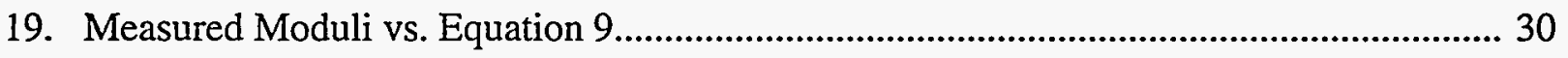

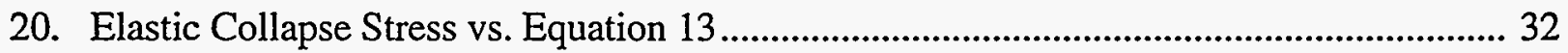

\section{TABLES}

No.

Page

I. Selected Formulations for Foam Specimens ........................................................... 10

II. Effect of Strain Rate on Properties of Crete Foam...................................................... 21 


\section{MECHANICAL PROPERTIES AND ENERGY ABSORPTION CHARACTERISTICS OF A POLYURETHANE FOAM}

\section{Introduction}

Polyurethane foams are used as encapsulants for electronic components to mitigate harsh thermal and mechanical shock environments and to provide electrical isolation. Historically, a principal constituent of these foam systems (e.g., BKC 44402) has been toluene diisocyanate (TDI), a suspect human carcinogen. DOE has directed that attempts be made to replace materials containing such suspect human carcinogens. To that end, the CRETE foam system was developed, based on the work done by Peter Rand of SNL/NM (Org. 1811) on a non-TDI encapsulation foam (BKC 44320) and on a non-TDI structural foam system adapted for encapsulation use by Tom Neet of AS/FM\&T (BKC 44307).(1) It is this new foam system that is the subject of this report.

The SNL/NM system, BKC 44320, uses the polyester polyol component found in the older TDI systems and a quasi-prepolymer made from polymeric methylene diisocyanate (PMDI). PMDI has a vapor pressure that is more than a thousand-fold lower than TDI, making it easier to keep airborne levels of isocyanate below $0.005 \mathrm{ppm}$, the Threshold Limit Value for methylene diisocyanate (MDI), the major component of PMDI. The AS/FM\&T foam, BKC 44307, is also based on PMDI but uses a polyether polyol. The PMDI and polyether constituents of the BKC 44307 have a higher functionality than the constituents of either BKC 44402 or BKC 44320 . The higher functionality of the BKC 44307 components results in a higher degree of cross-linking, yielding a stiffer, but more brittle foam than is the case for either the original BKC 44402 series or the BKC 44320 system. Both the TDI and PMDI systems use added water as a chemical blowing agent. Reaction of the water with isocyanate produces carbon dioxide that expands the foam. No physical blowing agents are used.

A major processing requirement for any high density encapsulation foam $\left(0.1-0.5 \mathrm{~g} / \mathrm{cm}^{3}\right)$ is that the rising foam system remain liquid-like for a long enough time to fill the entire mold volume and to wet out all of the components of the electronic assembly completely. Foam systems that gel considerably before reaching full expansion are clearly less desirable for encapsulation uses. For foams with a short "time to gel" (the curing reaction time) to "time to full rise" (the blowing reaction time) ratio, the amount of expansion that can occur after gelling depends on the temperature of the reaction mix and thus on the size of the pour. For example, it is often the case for small pours (often encountered in encapsulation applications), that the reaction temperature remains low. In such instances, the gel-to-rise time ratio is found to be considerably less than one and the foam is unable to expand completely after gelling to fill the mold. Experience has shown that foams with gel-to-rise ratios closer to unity are desired for small encapsulation applications.

Catalysts are usually added to balance the gelling and blowing reactions and give gel-to-rise ratios slightly less than one, often at the expense of reduced processing time or pot life. Both PMDI 
systems, BKC 44307 and BKC 44320 , therefore, employ tertiary amine catalysts, which were unnecessary in the TDI system, BKC 44402. In actual use, however, the BKC 44320 and BKC 44307 systems have been found to be fast rising foams with relatively low gel-to-rise ratios.

The formulation challenge for the CRETE program was to develop a foam system with processing times and mechancial and physical properties comparable to the original TDI system, BKC 44402. To delay the gel reaction and provide a more favorable gel-to-rise ratio, the functionality of the isocyanate components was lowered to 2.1 by the use of modified-MDI (MMDI) instead of the higher functionality PMDI components (2.3 to 2.7). The use of MMDI in CRETE foam also eliminated the need for a quasi-prepolymer employed in the 44320 and 44307 systems. Small amounts of tertiary amine catalyst, Polycat 17, were used to tailor the gel-to-rise ratio further and to optimize the processing of CRETE foam for encapsulation of electronic components. A detailed report describing the formulation and processing of CRETE is to be issued.(2)

Characterization of the tension, compression, and impact properties of the CRETE foam system was necessary before the foam could be used for weapon system application. The purpose of this work was three-fold. Our first goal was to measure the conventional "quasi-static" tensile and compressive mechanical properties of CRETE. Our second goal was to compare the energy absorption characteristics that can be derived from those measurements to a direct measure of energy absorption under high rate, impact conditions which may be more realistic of service environments. Lastly, the quasi-static measurements of elastic modulus and elastic collapse stress are reported and are related to the mechanics of cellular deformation.

The results and conclusions from the experiments described here are being used as a basis for improving the physical and mechanical properties of non-TDI polyurethane foams and for comparison to existing foams that are used for encapsulation purposes. 


\section{Experimental}

\section{Formulation of CRETE Foam System}

The components of CRETE rigid polyurethane foam are:

- Voranol 490:

A polyether polyol, made from polypropylene oxide and a sucrose/glycerin base, available from Dow Chemical. The manufacturer specifies the following properties:

$\begin{array}{ll}\text { Density }\left(25^{\circ} \mathrm{C}\right) & 0.11 \mathrm{~kg} / \mathrm{cm}^{3} \\ \text { Typical hydroxyl number } & 490 \mathrm{mg} \mathrm{KOH} \text { equiv/g of resin } \\ \text { Functionality } & 4.3 \text { (calculated) } \\ \text { Average Molecular Weight } & 460 \mathrm{~g} / \mathrm{mole} \\ \text { Viscosity }\left(25^{\circ} \mathrm{C}\right) & 5572 \mathrm{cps}\end{array}$

- DC193:

A silicone glycol copolymer surfactant from Air Products with an average hydroxyl number of 75 .

- Polycat 17:

A tertiary amine catalyst (trimethyl-N-hydroxyethyl propylene diamine) available from Air Products with an average hydroxyl number of 400 .

- Distilled water:

Added in various amounts as a chemical blowing agent producing carbon dioxide.

- Isonate 143L:

A modified methylene diisocyanate (MMDI) available from Dow Chemical. The manufacturer specifies the following properties for Isonate 143L:

$\begin{array}{ll}\text { Isocyanate Equivalent Weight } & 144.5 \mathrm{~g} \\ \text { NCO Content by Weight } & 29.2 \% \\ \text { Functionality } & 2.1 \\ \text { Viscosity }\left(25^{\circ} \mathrm{C}\right) & 33 \mathrm{cps}\end{array}$

The density of the CRETE foam system is varied by changing the amount of added water, thereby controlling the amount of rise in the foam. The amount of catalyst and surfactant are also varied slightly to optimize processing and foam properties.

A semi-empirical model has been developed to determine the near-optimum amounts of catalyst and surfactant as a function of density and will be described in a subsequent SAND report on the formulation of non-TDI encapsulant foam systems.(2) A spreadsheet program that uses these semi-empirical relations to derive a CRETE formula based on a desired part density and size was used to determine the specific sample CRETE formulas tested in this study. Examples of some, but not all, of the actual formulations used in the present work on the following page. 
TABLE I: SELECTED FORMULATIONS FOR FOAM SPECIMENS

\begin{tabular}{|l|c|r|r|r|r|}
\hline $\begin{array}{l}\text { Desired Density } \\
\left(\mathrm{g} / \mathrm{cm}^{3}\right)\end{array}$ & 0.17 & 0.22 & 0.28 & 0.34 & 0.42 \\
\hline \hline $\begin{array}{l}\text { Expected Free Rise } \\
\text { Density }\left(\mathrm{g} / \mathrm{cm}^{3}\right)\end{array}$ & 0.10 & 0.13 & 0.16 & 0.19 & 0.24 \\
\hline \hline Voranol 490 & $100 \mathrm{phr} *$ & $100 \mathrm{phr}$ & $100 \mathrm{phr}$ & $100 \mathrm{phr}$ & $100 \mathrm{phr}$ \\
\hline DC193 & $2.53 \mathrm{phr}$ & $2.45 \mathrm{phr}$ & $2.05 \mathrm{phr}$ & $1.90 \mathrm{phr}$ & $1.73 \mathrm{phr}$ \\
\hline Polycat 17 & $0.50 \mathrm{phr}$ & $0.47 \mathrm{phr}$ & $0.49 \mathrm{phr}$ & $0.54 \mathrm{phr}$ & $0.63 \mathrm{phr}$ \\
\hline Water & $1.15 \mathrm{phr}$ & $0.78 \mathrm{phr}$ & $0.58 \mathrm{phr}$ & $0.46 \mathrm{phr}$ & $0.34 \mathrm{phr}$ \\
\hline Isonate $143 \mathrm{~L}$ & $152.2 \mathrm{phr}$ & $146.0 \mathrm{phr}$ & $142.6 \mathrm{phr}$ & $140.5 \mathrm{phr}$ & $138.0 \mathrm{phr}$ \\
\hline
\end{tabular}

* parts per hundred resin

The above formulas assume a packing factor of 1.75 (packed density/free rise density) and an isocyanate index of 105 (5\% excess of isocyanate groups). The free rise density is measured for a 100 gram sample poured from a 200 gram batch of CRETE foam expanding in a $500 \mathrm{ml}$ polyethylene cup. The free rise density depends on the temperature of the reaction and thus will vary slightly depending on the size of the batch.

\section{Processing CRETE Foam System}

CRETE foam samples were generated by the addition of the isocyanate component (Isonate 143L) to the polyol component premixed with DC193, Polycat 17, and water. The resulting reaction mixtures were stirred at $1500 \mathrm{rpm}$ for 60 seconds using a Conn mixing blade ( $51 \mathrm{~mm}$ diameter). The mixed products were then poured into cylindrical molds at room temperature. The molds were lightly waxed with a non-silicone mold release. The molds were then closed, and the foam was allowed to expand to fill the closed molds at a packed density approximately 1.75 times the expected free rise density. The reaction times for the CRETE system are generally less than eight minutes from the time of complete mixing. The samples were post-cured in an oven for a minimum of eight hours at $66^{\circ} \mathrm{C}$. Right circular samples of foam were cored from the molded samples with the cylinder axis parallel to the direction of the foam rise. None of the core samples included the foam skin or any material less than $3 \mathrm{~mm}$ below the surface. The density of each foam core was measured and was usually slightly less than the density of the entire sample including the foam skin. These cored samples were used in the mechanical testing reported below.

\section{Mechanical Testing}

Room temperature uniaxial tension and compression mechanical properties were evaluated as a function of foam density using a conventional Instron mechanical test frame. Most tests were conducted at an initial strain rate of $1.7 \times 10^{-4} \mathrm{~s}^{-1}$. Some tests were run at rates between $1.7 \times 10^{-5}$ and $1.7 \times 10^{-2} \mathrm{~s}^{-1}$ in order to examine strain rate affects. All specimens were instrumented with a mechanically attached extensometer for displacement measurement. Tension and compression specimens are shown in Figure 1. The tension specimens had a gage length of $25.4 \mathrm{~mm}$ and a reduced gage diameter of $19.0 \mathrm{~mm}$ and were bonded to steel pull studs. The reduced gage section insured that failure occurred within the specimen between the attachment points of the extensometer and not at the bondline between the foam and the pull studs. The compression specimens were simple, right circular cylinders $50.8 \mathrm{~mm}$ long and $28.7 \mathrm{~mm}$ in diameter. 

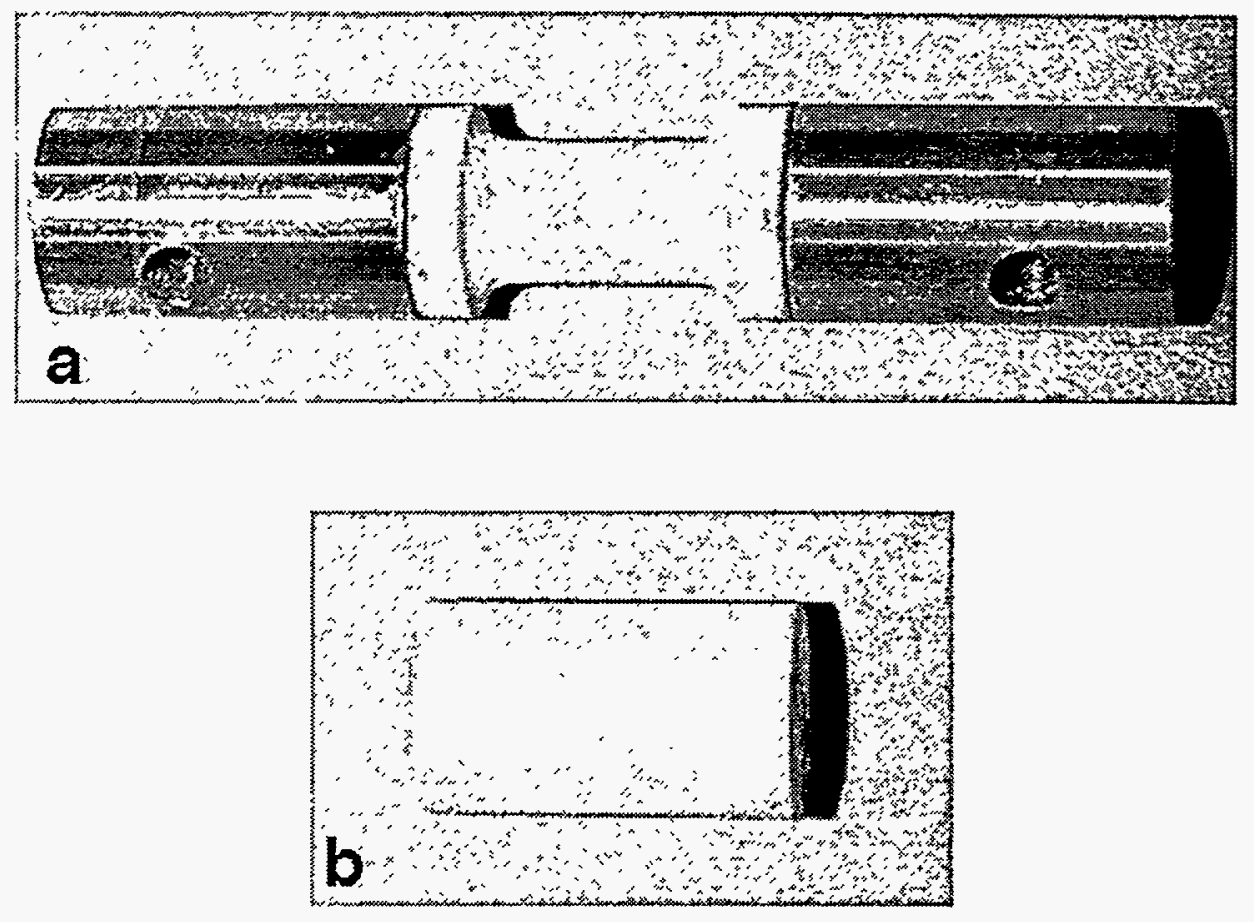

Figure 1. Specimen geometries used in this study. (a) Tension specimen had a $25.4 \mathrm{~mm}$ gage length with a $19.0 \mathrm{~mm}$ reduced gage diameter. Steel pull studs were bonded to the specimen ends for mounting in the test frame. (b) Compression and impact specimens were simple free standing right cylinders $50.8 \mathrm{~mm}$ long and $28.7 \mathrm{~mm}$ in diameter.

Mechanical properties were measured for foam densities between $0.12 \mathrm{~g} / \mathrm{cm}^{3}$ and $0.61 \mathrm{~g} / \mathrm{cm}^{3}$. For tension testing, modulus $\left(\mathrm{E}^{\star}\right)^{f}$, ultimate tensile strength (UTS) and energy absorption/unit volume (toughness) were measured. The latter parameter was calculated as the area under the tensile stress-strain curve (see Figure 2). For compression testing where macroscopic fracture did not occur, tests were run to engineering strains of approximately $0.3(30 \%)$. Strength and energy absorption at $0.1(10 \%)$ strain were recorded for comparison. An additional parameter for compression testing, the elastic collapse stress, $\sigma^{*}{ }_{\text {el }}$, a broad plateau region subsequent to linear loading, was also measured.

Specimens for impact testing had the same geometry as the compression specimens. These tests were conducted on a Dynatup ${ }^{\circledR}$ Model 8250 drop weight impact tester coupled to a digital data acquisition and analysis system. The test frame can be operated in either gravity mode or with pneumatic assist. In the former case up to $300 \mathrm{~J}$ of energy can be delivered to a test specimen while in the latter case up to $840 \mathrm{~J}$ can be delivered with impact velocities of up to $13.4 \mathrm{~m} / \mathrm{s}$. The high speed data acquisition system, which records the output of an instrumented tup (load cell), has $1 \mu$ s resolution and can acquire a complete loading (impact) event in as little as $4 \mathrm{~ms}$. The

$f$ terms or values annoted by " $\star *$ " refer to parameters of the foam, other terms annotated by "s" refer to parameters related to the solid polymer. 
software analyses the deceleration of the crosshead between successive data points from which it determines the instantaneous velocity. Energy absorption of a test specimen is then determined by knowing the instantaneous force (from the tup) and the integration of the time rate of change of the velocity of the crosshead as the specimen is compressed.

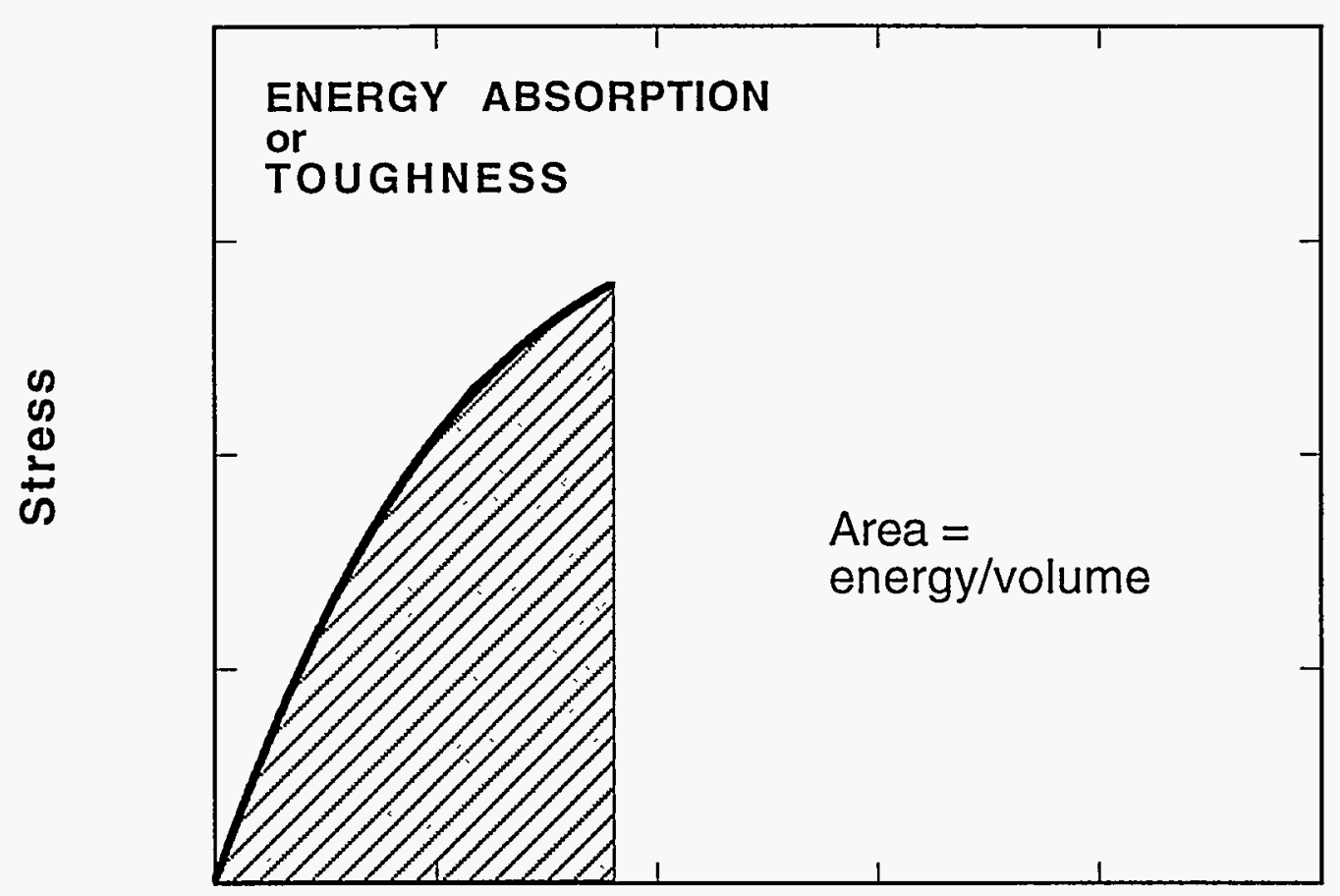

\section{Strain}

Figure 2. Schematic illustration of the calculation of toughness or energy absorption from either a tension or compression stress-strain curve. The energy absorption is the area under the curve either to the point of failure or to some pre-determined strain value. 


\section{Results and Discussion}

\section{Tension}

Figure 3 shows a series of tensile tests for foam specimens having a density of $0.24 \mathrm{~g} / \mathrm{cm}^{3}$. For any given material condition (density), test results are quite reproducible. The modulus (defined as the slope of the linear loading portion of the stress strain curve) for the five tests shown in Figure 3 is $159.0 \pm 10.5 \mathrm{MPa}$. The ultimate tensile strength of the foam is $3.76 \pm 0.07 \mathrm{MPa}$ while the fracture strain is $0.039 \pm 0.003$. The energy absorption of this density foam was derived from the area under the stress-strain curves as described above and found to be $0.095 \pm 0.012 \mathrm{~J} / \mathrm{cm}^{3}$. This general reproducibility was typical of all tension and compression testing.

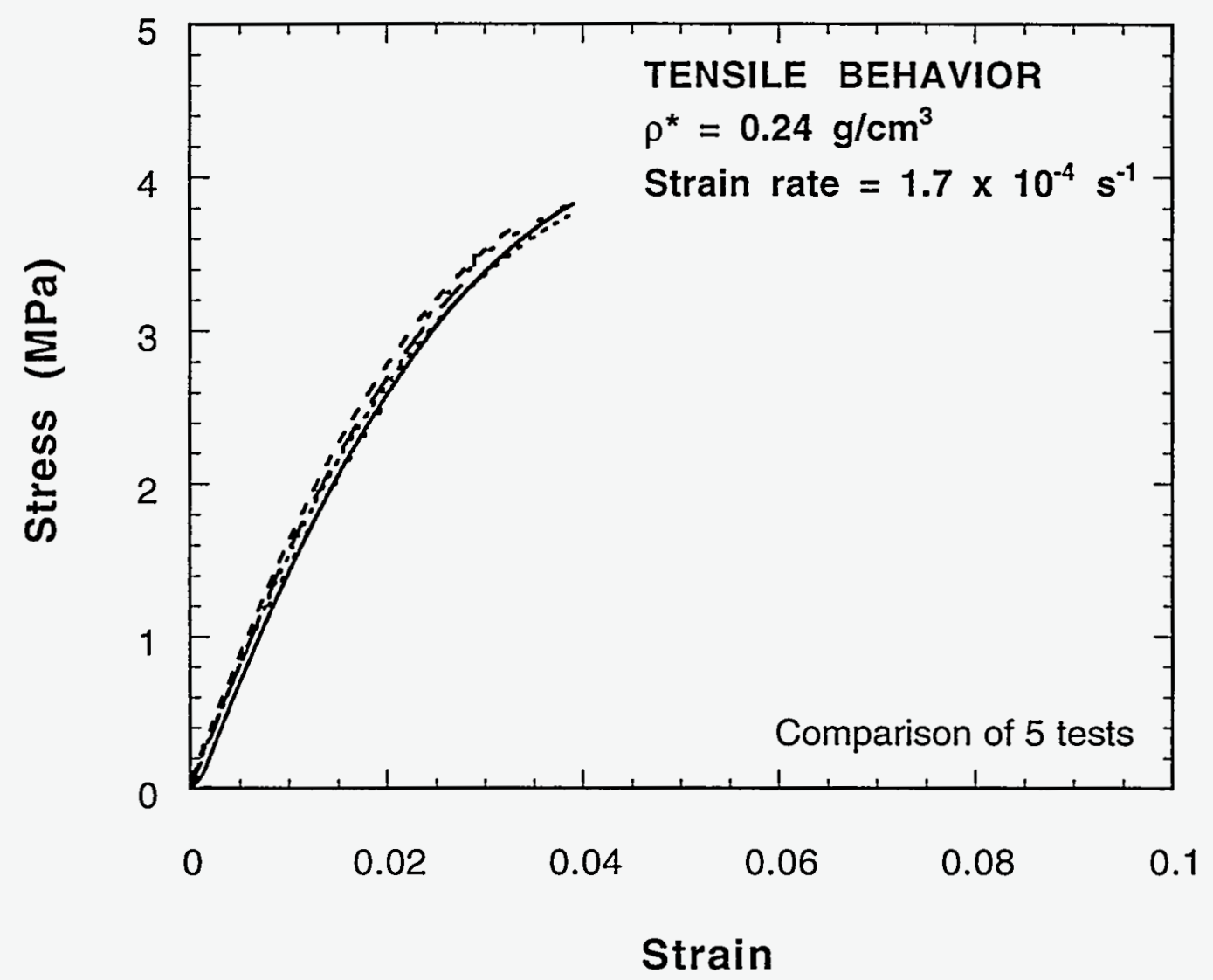

Figure 3. Comparison of five tensile curves for foam specimens, $\rho^{\star}=0.24 \mathrm{~g} / \mathrm{cm}^{3}$.

The modulus as a function of foam density is shown in Figure 4. Modulus of the foam exhibits a power-law dependence with respect to the density of the form :

$$
E^{*} \propto\left(\rho^{*}\right)^{n}
$$

where $E^{*}$ is the modulus of the foam, $\rho^{*}$ is the foam density and $n$ is the density exponent. It will be shown later that there are sound theoretical reasons to not consider the density exponent as a constant over all possible foam densities. However, over the range of density shown in Figure 4, the data are well fit for a density exponent of $n=1.6$. 


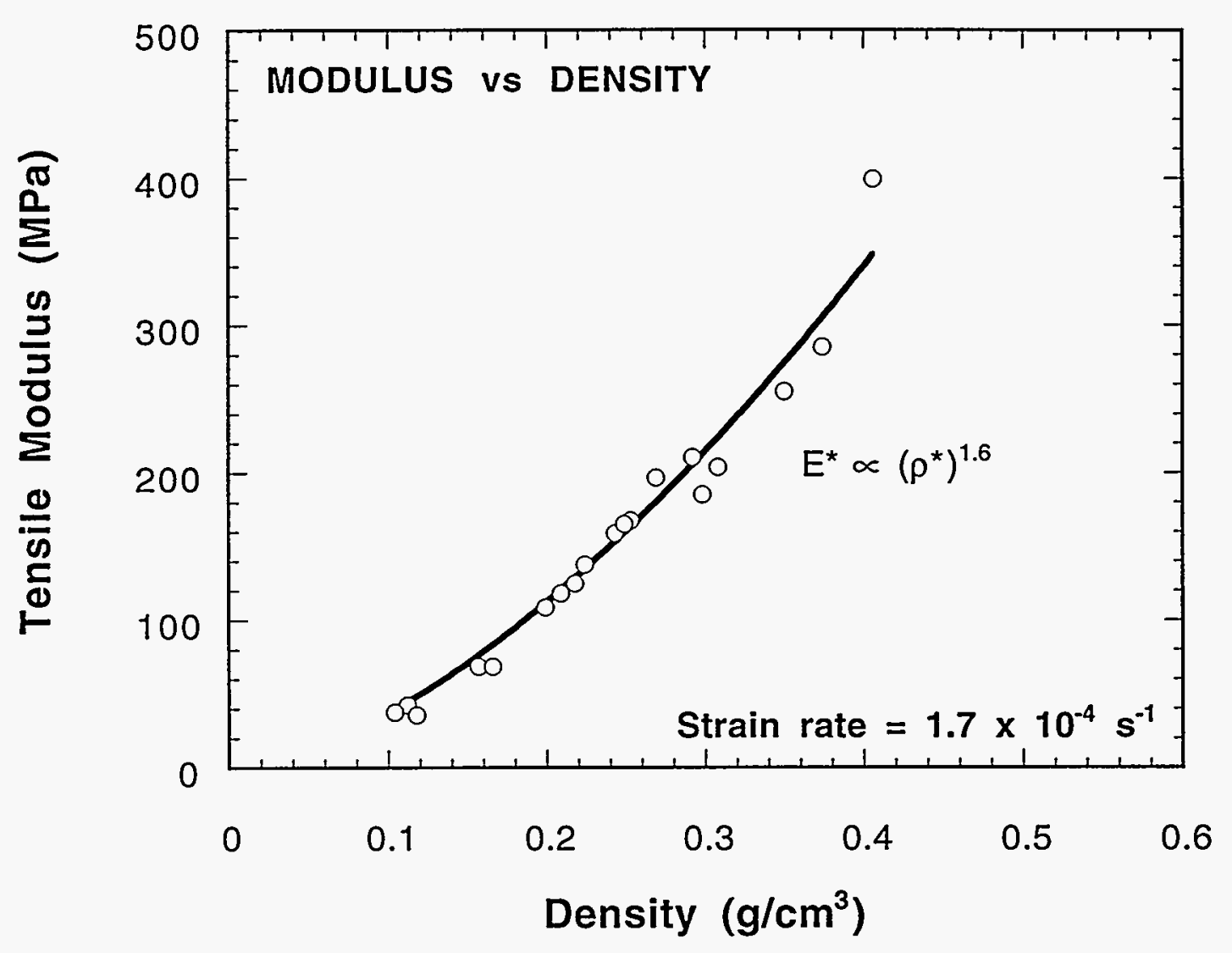

Figure 4. Foam modulus exhibits a power-law dependence with respect to density.

Energy absorption of the material is determined as the area traced out by the stress-strain curves as described in the Experimental Section. Figure 5 shows the results for the tension testing over the entire range of foam densities examined. The results indicate that energy absorption of the material increases linearly with increasing foam density. Values range from a low of $0.04 \mathrm{~J} / \mathrm{cm}^{3}$ for foam with a density of $0.104 \mathrm{~g} / \mathrm{cm}^{3}$ to $0.16 \mathrm{~J} / \mathrm{cm}^{3}$ for foam having a density of $0.39 \mathrm{~g} / \mathrm{cm}^{3}$. It will be shown that the energy absorption values are quite low compared to other methods of testing. The energy absorption values obtained via tensile testing are controlled entirely by the brittle nature of the material in tension and therefore ought not be used to characterize the intrinsic crush capabilities of the material. However, it should be noted that energy absorption values derived from tension data may have validity in certain unique environments where tensile loading is important.

\section{Compression}

Figure 3 reveals that the foam is quite brittle in tension - there is little or no macroscopic yielding in tension prior to fracture. Because of the inherent lack of tensile ductility, it is clear that tension testing is not the most appropriate method for evaluating the mechanical properties of a material whose primary mechanical requirement is compressive shock mitigation and energy absorption. 


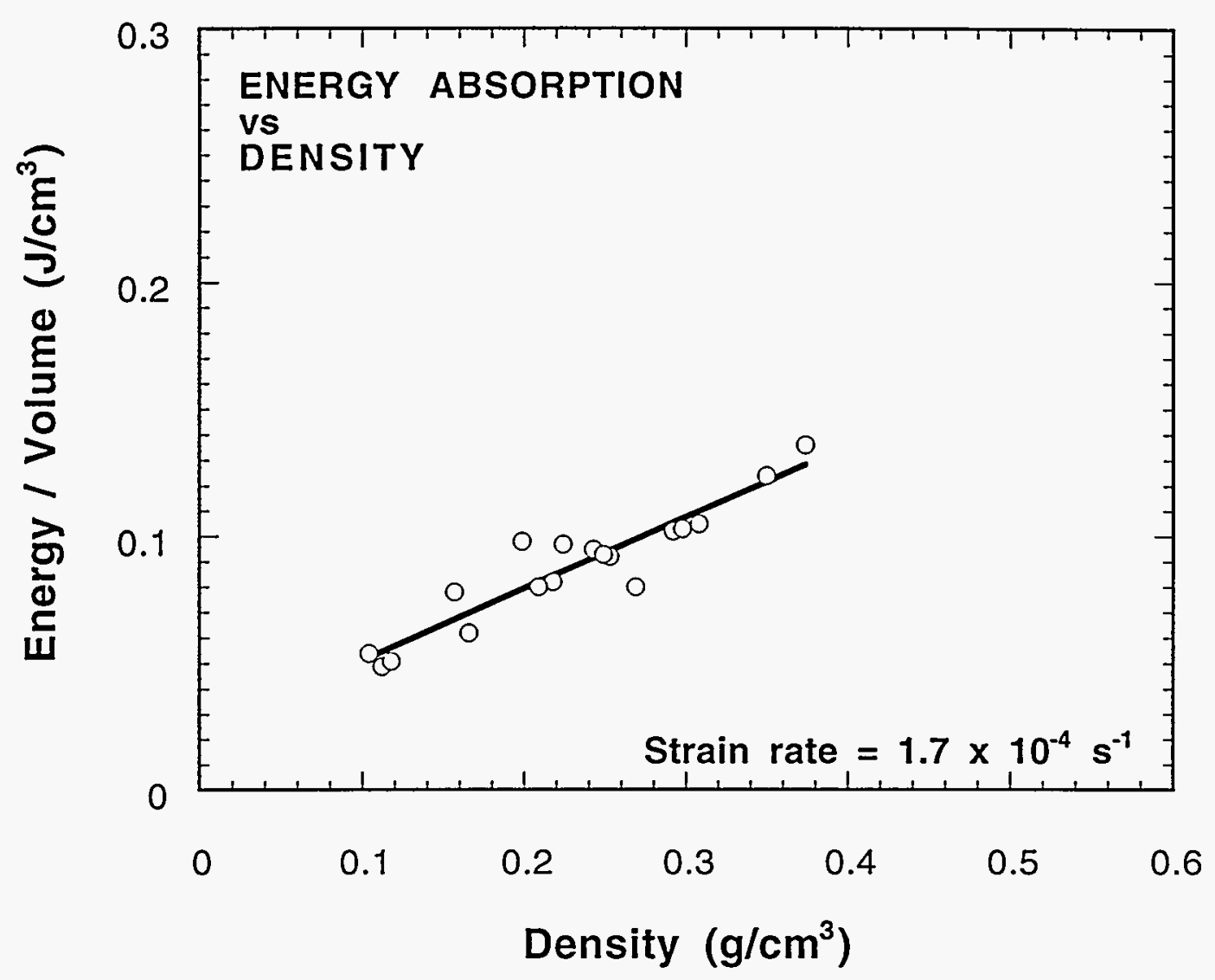

Figure 5. Energy absorption as a function of density for tensile tests. The results indicate that energy absorption of the material increases linearly with increasing foam density.

A companion series of compression tests were performed on the material to determine the energy absorption characteristics under somewhat more realistic conditions. A typical compression test is shown in Figure 6 for a foam having a density of $0.15 \mathrm{~g} / \mathrm{cm}^{3}$. In compression, the foam specimens show relatively abrupt yielding followed by a sustained plateau region. At the lower densities, such as that shown in Figure 6, the stress after the plateau actually drops, giving rise to a yield point-like behavior. The broad plateau region results from the elastic collapse or cell wall buckling of the foam.(3) The stress begins to increase subsequent to this plateau region as the foam begins to densify. Unlike the tests performed in tension, fracture is inhibited by the absence of tensile stresses and as a result, engineering strains in excess of 50\% have been measured with little observable indication of fracture. In order to expedite testing, compression strains were limited to 0.3 which was sufficient to characterize the modulus and plateau stress values for each specimen.

Mechanical properties during the early stages of compression are essentially identical to those observed in tension. Figure 7 compares the tension and compression behavior for a foam having a density of $0.24 \mathrm{~g} / \mathrm{cm}^{3}$. Both tests were conducted at the same strain rate. The curves overlay up until the point of tensile failure, suggesting that the microstructural processes governing elastic deformation and low strain response in both tension and compression are identical. 


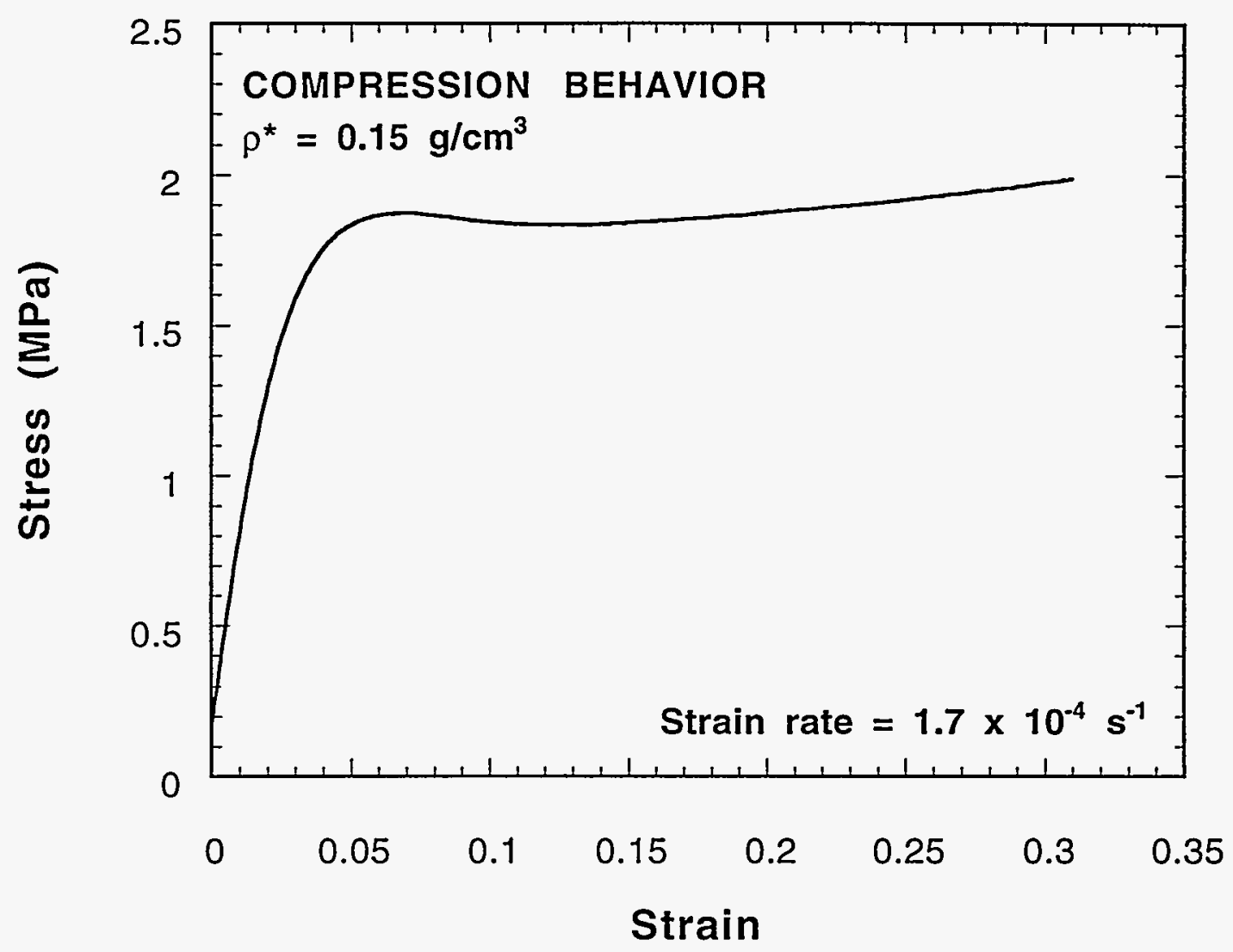

Figure 6. Typical compression test results for a foam having a density of $0.15 \mathrm{~g} / \mathrm{cm}^{3}$. A relatively abrupt yield point is followed by a sustained plateau region. The stress begins to increase subsequent to this plateau region as the foam begins to densify.

For a given foam density, tests performed in compression were found to have the same general reproducibility as that found for tests performed in tension. As an example, Figure 8 shows the results for duplicate tests on a foam having a density of $0.26 \mathrm{~g} / \mathrm{cm}^{3}$. Note that for all compression testing, absorption energy is calculated at a constant reference strain equal to $0.10(10 \%)$. Because of this, the energy absorption values for compression testing do not reflect intrinsic material properties. Rather, they are useful only as a means to compare toughness characteristics as a function of density.

Moduli, derived from the compression tests, as a function of foam density are shown in Figure 9. In this figure, the compression moduli are superimposed on the data shown in Figure 4. It is clear that compression testing yields the same moduli as tensile testing. When all of the data are fit to a power-law relationship, the density exponent, $\mathrm{n}$, is still equal to 1.6 , as it was for the tension only moduli in Figure 4. 


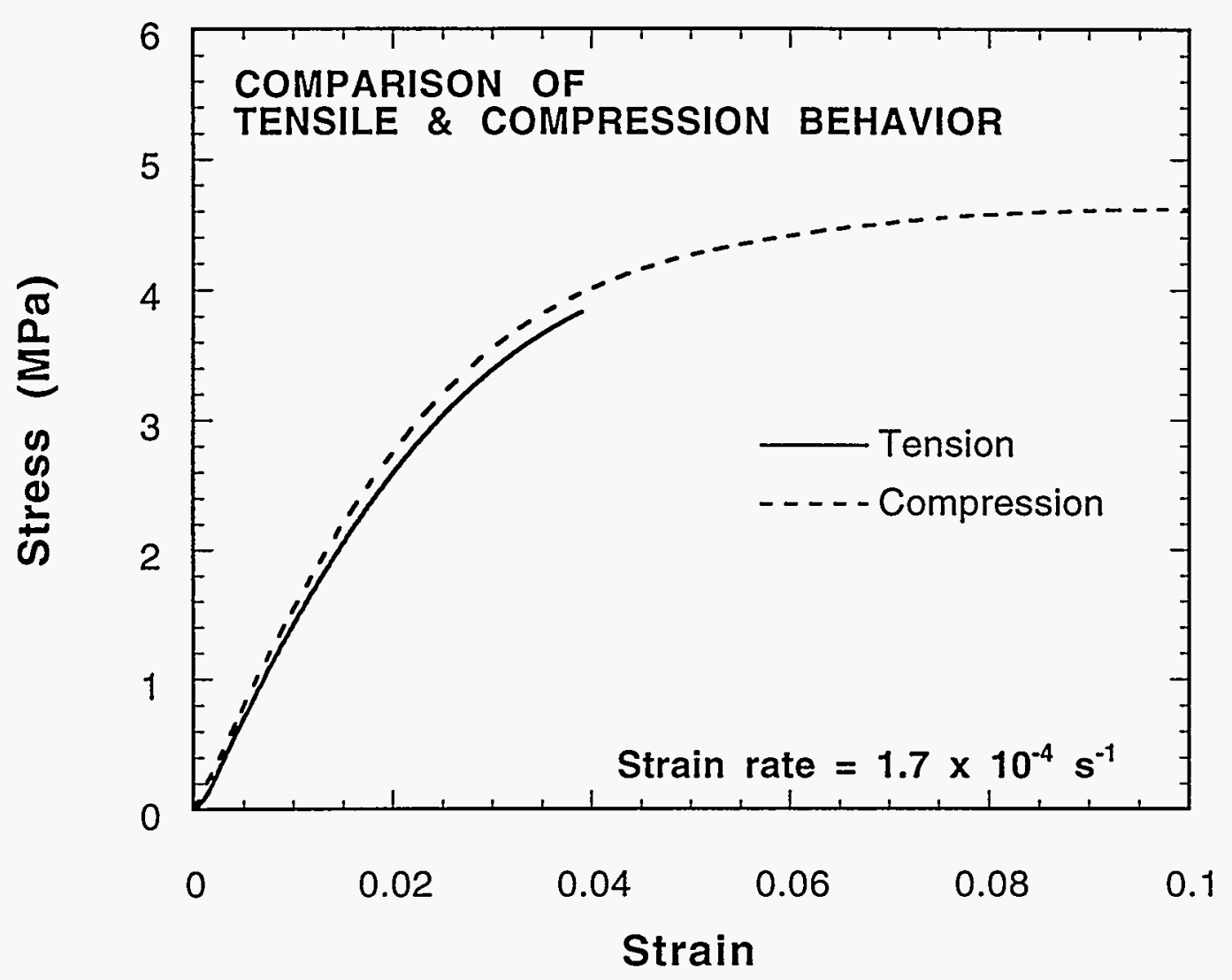

Figure 7. Tension and compression behavior for foam specimens of the same density $\left(0.24 \mathrm{~g} / \mathrm{cm}^{3}\right)$. Compression trace overlays a companion tension test up to the point of tensile failure.

Figure 10 shows the plateau stress for the foam specimens as function of density. This plateau stress, also called the elastic collapse stress, $\sigma^{*}{ }_{\text {el }}$, is important in the design of cushions for shock or impact mitigation as it represents the onset of the mechanical instability of the foam microstructure(3). It too, exhibits a power-law dependence with respect to foam density although somewhat higher than the density exponent for the modulus.

The energy absorption of the foam vs. density up to the reference strain of 0.1 is shown in Figure 11 along with the data from Figure 5 for tension testing. Values range from a low of $0.10 \mathrm{~J} / \mathrm{cm}^{3}$ for foam with a density of $0.12 \mathrm{~g} / \mathrm{cm}^{3}$ to $1.20 \mathrm{~J} / \mathrm{cm}^{3}$ for foam having a density of $0.495 \mathrm{~g} / \mathrm{cm}^{3}$. It is clear that total energy absorption capacity of the foam in compression far exceeds that in tension for the entire range of density examined. The comparison would be even more striking for energy absorption values computed at higher reference strains. The difference between the tension and compression derived energy values results directly from the inherent brittleness of the material under tensile loading which limits ductility to less than about 0.05 (5\%). The relationship between foam density and absorption energy (in compression) arises directly from the power-law relationship between compressive strength and density as shown in the previous figure. 


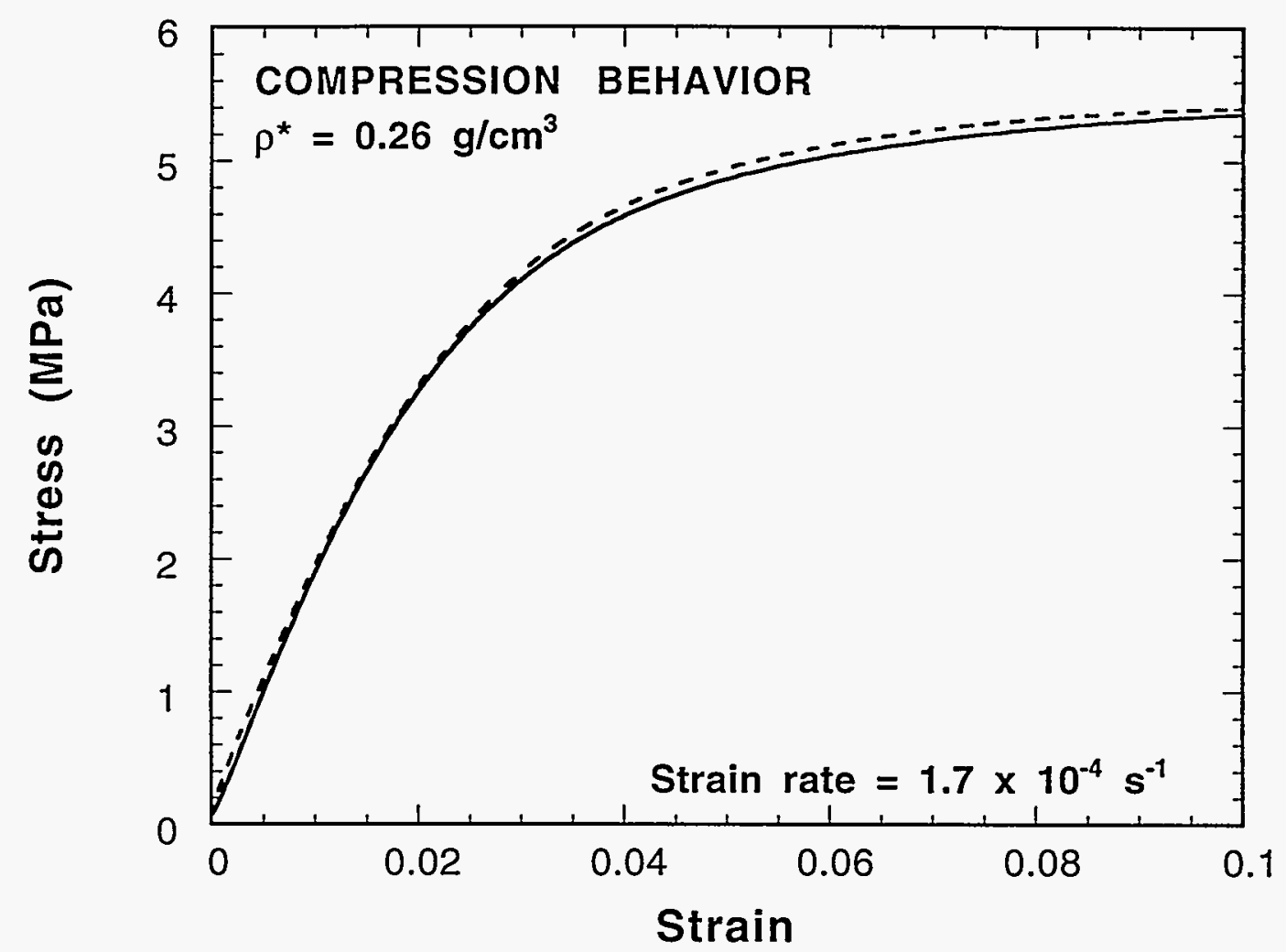

Figure 8. Reproducibility of compression tests for a foam having a density of $0.26 \mathrm{~g} / \mathrm{cm}^{3}$.

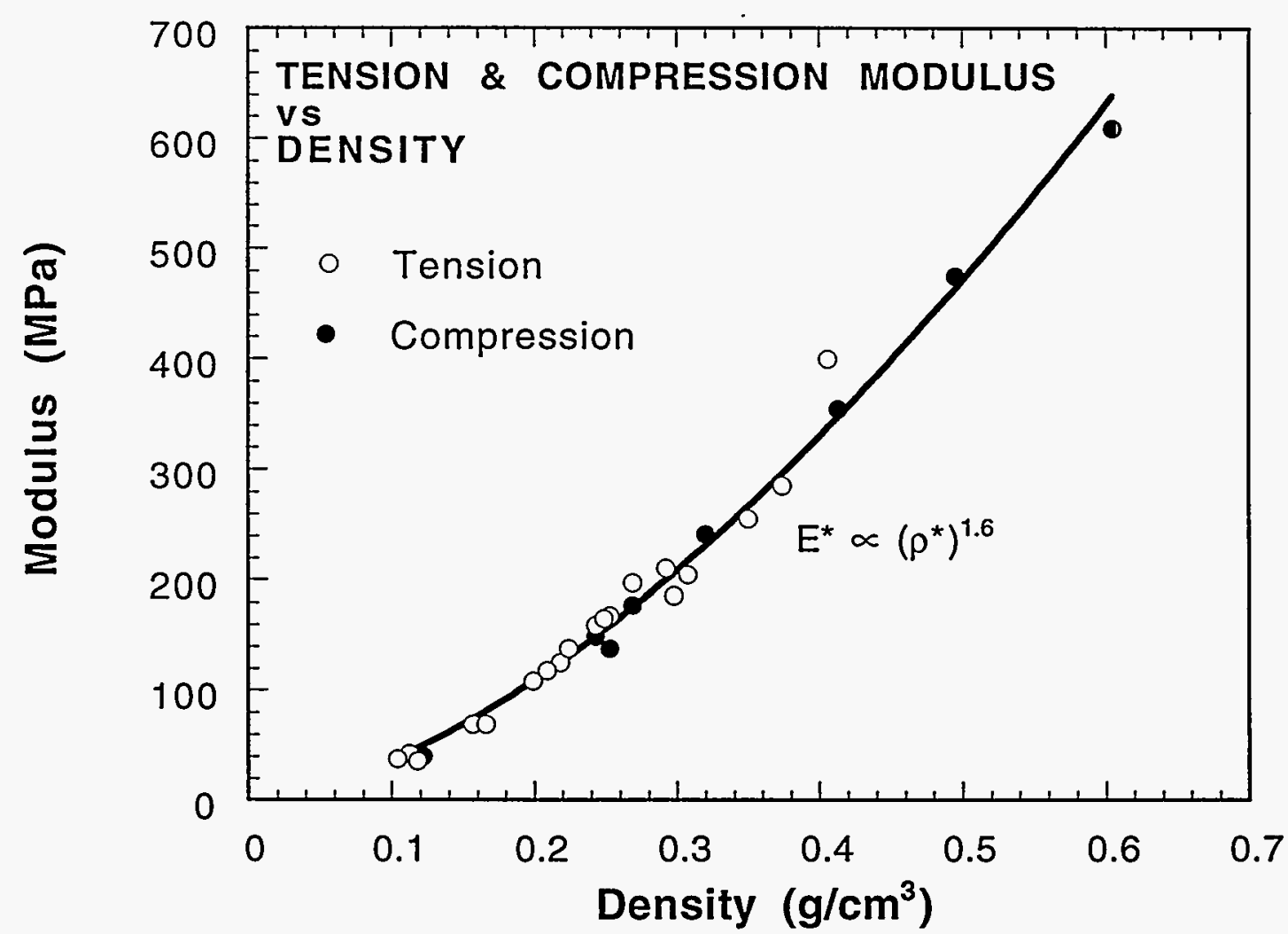

Figure 9. Density dependence of the foam modulus in tension and compression. 


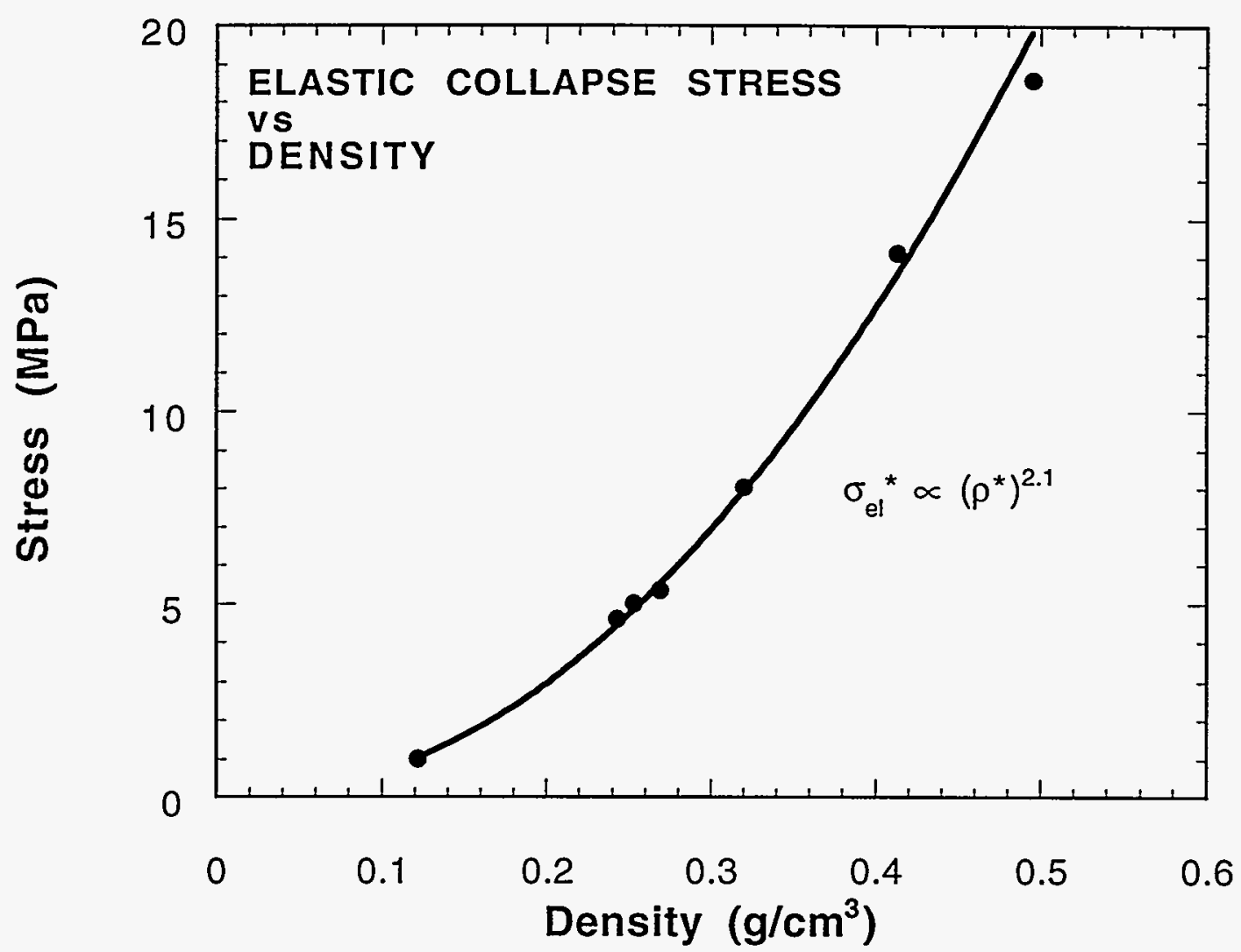

Figure 10. Elastic collapse stress for the foam specimens as function of density. A power-law dependence with respect to foam density is evident.

Although quasi-static compression testing represents a more realistic test condition than tensile testing, it is still of only limited value with respect to characterizing the shock mitigating (i.e., high rate) qualities of a foam encapsulant. The limitations stem from the strain rate sensitive nature of the viscoelastic polyurethane. The rate sensitivity of the mechanical properties of the foam is illustrated in Figure 12. This figure compares a series of compression tests for specimens tested at strain rates that varied over three orders of magnitude $\left(\rho^{\star}=0.24 \mathrm{~g} / \mathrm{cm}^{3}\right)$. Over the range of strain rates examined, there is little change in the modulus of the foam (within the precision of the measurement). However, the plateau stress is found to increase monotonically with strain rate and as a result, the energy absorption values (again for reference strains of 0.10 ) also increased with increasing strain rate. The influence of strain rate on these properties is summarized in Table II. Because of the rate sensitivity of the strength of the foam, the use of quasi-static testing to assess the energy absorption capabilities of a material will result in measured values that are not indicative of dynamic material properties. Rather, the results will depend entirely on the specific test conditions. 


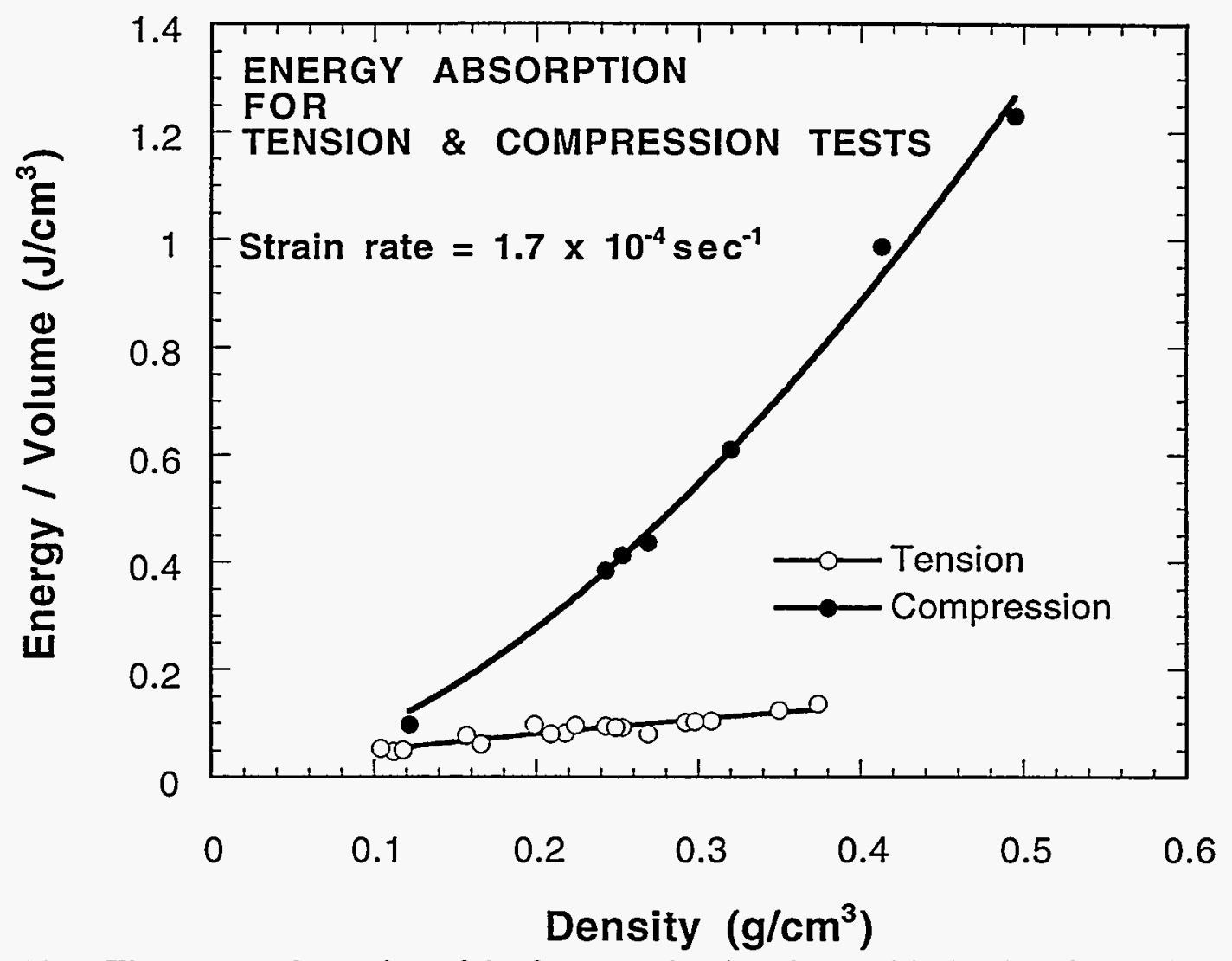

Figure 11. The energy absorption of the foam vs. density along with the data from Figure 5 for tension testing. Energy absorption capacity of the foam in compression far exceeds that in tension for the entire range of density examined.

\section{Impact Testing}

The rate sensitivity of the mechanical properties of the foam as illustrated in Figure 12 and Table II indicates that quasi-static testing cannot be used to quantitatively assess the energy absorption characteristics of polyurethane foams under shock loading. Under such conditions, where strain rates are many orders of magnitude greater than those that can be achieved using conventional mechanical test capabilities. For service environments that involve shock mitigation, what is needed is a high rate test method that can capture the dynamic response of the foam under loading rates that more closely correspond to impact conditions. The method chosen for the present studies involves the use of an instrumented drop weight impact tester. Depending on the sample geometry and test configuration, the apparatus can be used to simulate a wide range of testing requirements. For example, the fracture toughness of a material may be studied by examining the response of notched specimens to an impact load. Alternatively, the resistance of a material to penetration can be examine with the use of specimen plaques and either blunt or sharp impact tips.

For the present study, a series of drop weight impact tests were conducted on free standing, right circular cylinders having the same dimensions as the compression specimens. This specimen geometry was chosen because it most closely simulated the loading conditions expected in the service environment and because it afforded a direct comparison to the compression testing 
described above. The effective strain rates generated in these tests were $\approx 70 \mathrm{~s}^{-1}$ or nearly $4 \times 10^{5}$ times higher than the baseline strain rate used in the tension and compression testing.

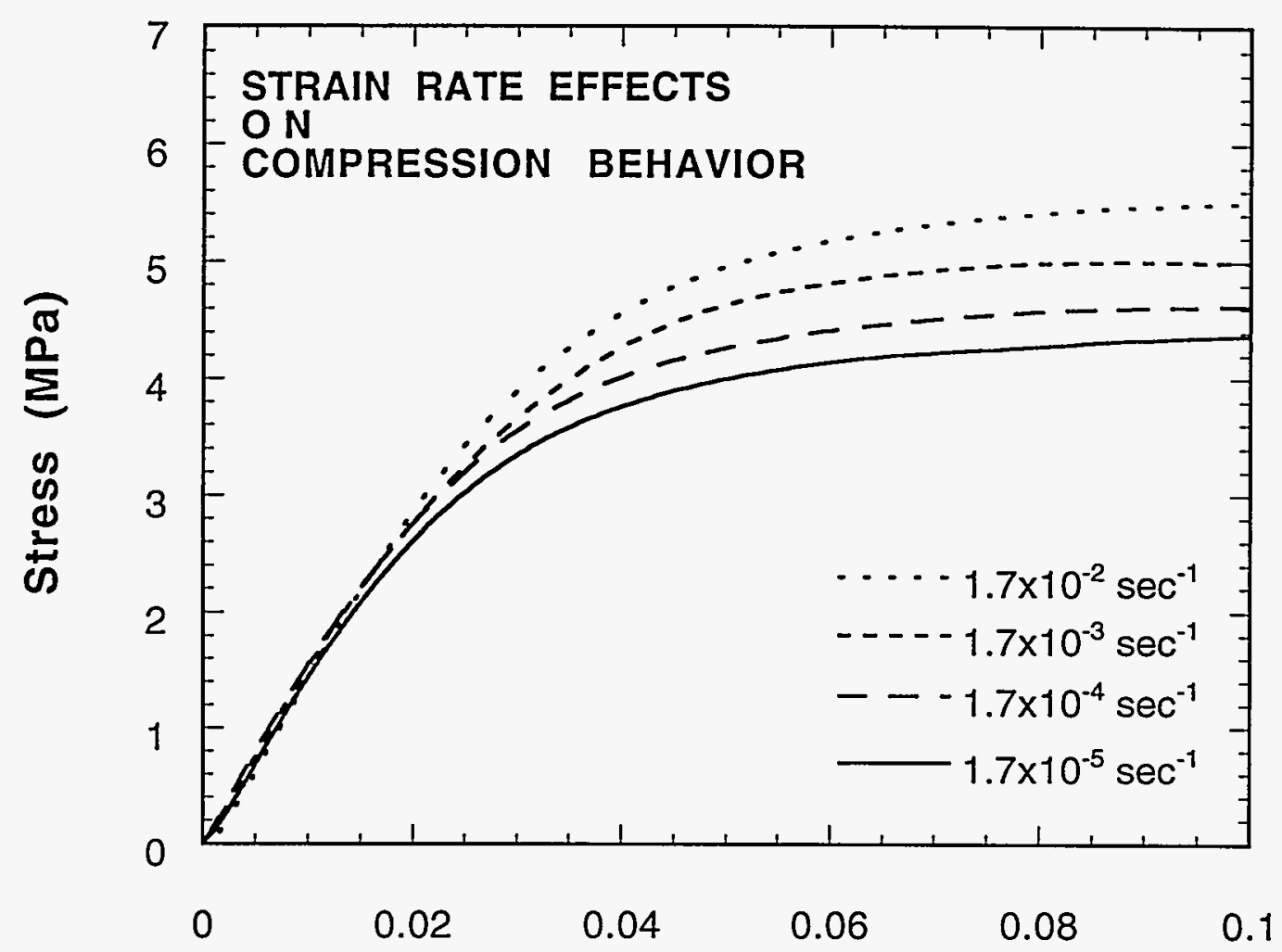

Strain

Figure 12. Effect of strain rate on compression behavior of foam having a density of $\rho^{\star}=0.24 \mathrm{~g} / \mathrm{cm}^{3}$.

TABLE II: EFFECT OF STRAIN RATE ON PROPERTIES OF CRETE FOAM

\begin{tabular}{|c|c|c|c|}
\hline $\begin{array}{c}\text { Strain Rate } \\
\left(\mathrm{s}^{-1}\right)\end{array}$ & $\begin{array}{c}\text { Modulus } \\
(\mathrm{MPa})\end{array}$ & $\begin{array}{c}\text { Plateau Stress } \\
(\mathrm{MPa})\end{array}$ & $\begin{array}{c}\text { Energy Absorption } \\
\left(\mathrm{J} / \mathrm{cm}^{3}\right)\end{array}$ \\
\hline \hline $1.7 \times 10^{-2}$ & 149 & 5.5 & 0.45 \\
\hline $1.7 \times 10^{-3}$ & 149 & 5.0 & 0.43 \\
\hline $1.7 \times 10^{-4}$ & 157 & 4.6 & 0.39 \\
\hline $1.7 \times 10^{-5}$ & 138 & 4.4 & 0.37 \\
\hline
\end{tabular}

An important characteristic of the impact tests performed here was that the test specimens all failed catastrophically. Thus, unlike the compression tests, where energy absorption was determined for some arbitrary strain, impact testing yielded intrinsic energy absorption values for the material. We qualify this statement by noting that the values measured are still dependent on 
the specimen geometry and the manner in which the specimens are supported and impacted. Testing specimens of entirely different geometries (for example, unsupported plaques) would undoubtedly yield different, although self-consistent results.

Figure 13 shows the results for a series of tests performed on foam specimens having a density of $0.27 \mathrm{~g} / \mathrm{cm}^{3}$. The figure shows both the stress (solid lines) and energy absorption (broken lines) as a function of time. Note that the entire impact events span less than $4 \mathrm{~ms}$. The loading (stress) ramps are quite reproducible up to the maximum load. Peak stresses are reached at $\approx 1 \mathrm{~ms}$. Oscillations in the stress traces can be seen and are the result of mechanical ringing induced in the load cell. However, these oscillations are small and have little influence on the determination of energy absorption. After about $1 \mathrm{~ms}$, the stress begins to fall off as the specimens begin to fail. In each case, failure is catastrophic, with the specimens shattering into many small irregularly shaped fragments. Variations in the rate of unloading is commonly observed due to differences in the way the specimens shatter. Identifying the precise point (in time, stress or strain) of specimen failure is problematic. We define failure to have occurred when the load drops to $60 \%$ of the peak load. This generally corresponds to the point at which the energy absorption traces begin to diverge. In Figure 13, the $60 \%$ of peak load point is identified by the arrow. The traces shown in Figure 13 are typical of the impact response of the foam at all densities.

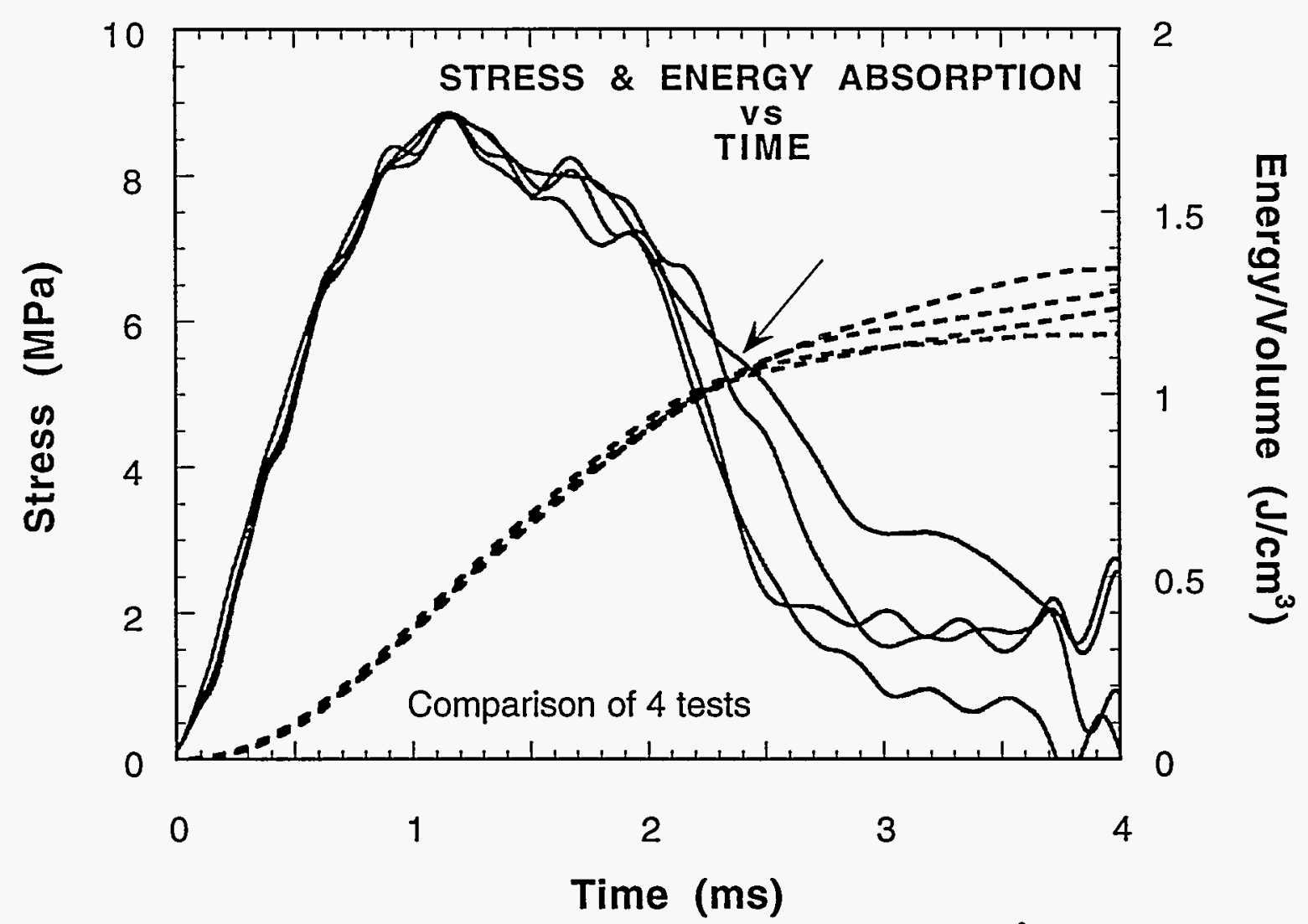

Figure 13. Dynamic response of foam having a density of $0.27 \mathrm{~g} / \mathrm{cm}^{3}$. The figure shows both the change in stress (solid lines) and the energy absorption (broken lines) as a function of time. 
Figure 14 shows the maximum stresses developed in the foam specimens for all three test techniques. The ultimate tensile strength (tension) is low over the entire range of foam densities reflecting the inherent brittle nature of the material. The compression data represent the plateau or collapse stress shown in Figure 10 which is fit to the power-law relationship previously defined. The stresses generated in the impact testing are greater than those in either of the quasi-static test types and unlike the compression testing represent true limiting values for the material under a specific set of dynamic conditions.

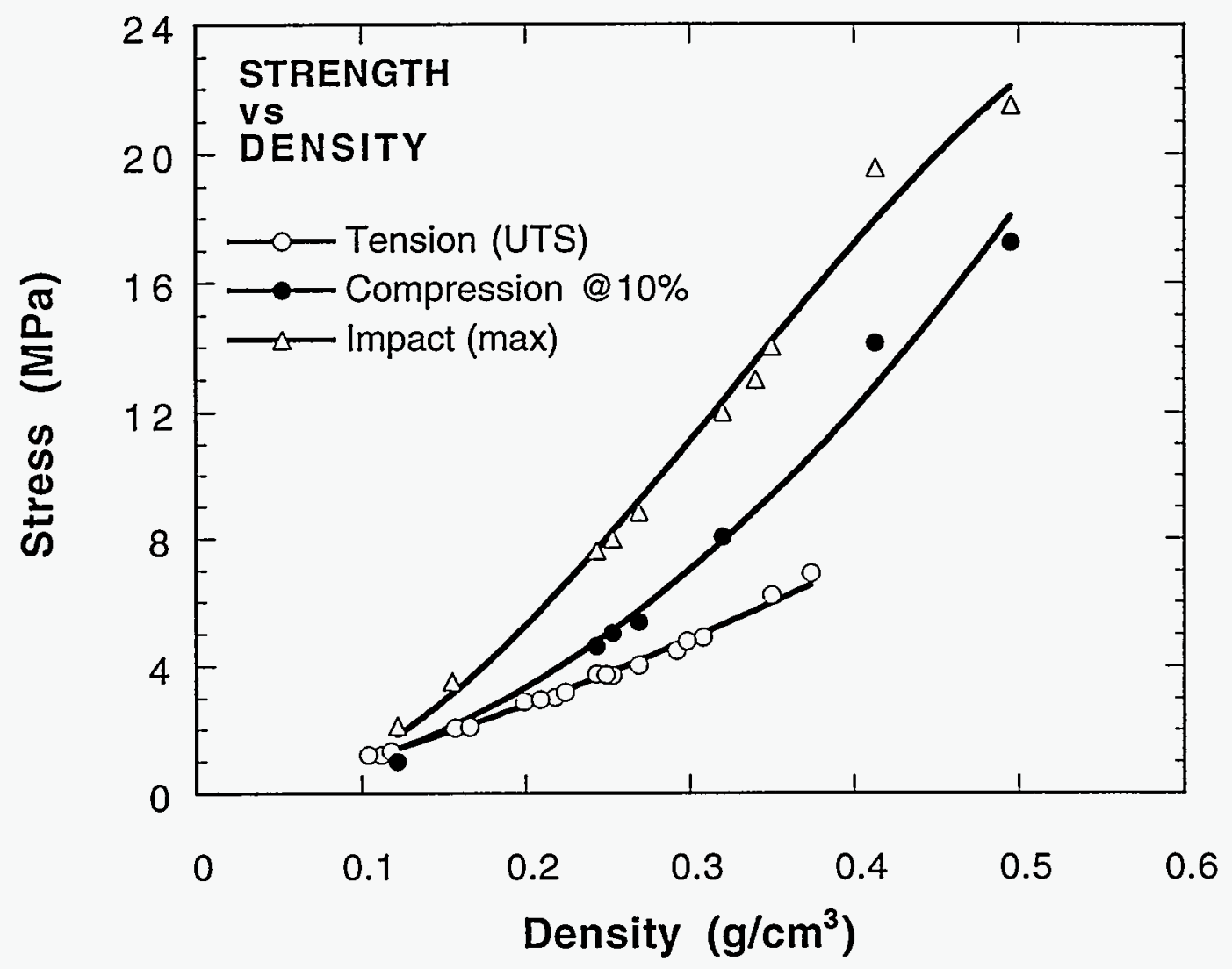

Figure 14. Maximum stresses developed in the foam specimens for all three test techniques. The tensile strength is low over the entire range of foam densities reflecting the inherent brittle nature of the material. The compression data represent the elastic collapse stress shown in Figure 10. The stresses generated in the impact testing are greater than those in either of the quasi-static test types.

Figure 15 shows the dynamic energy absorption of the foam vs. density. The figure reveals that energy increases monotonically with density up to a maximum of $\approx 1.4 \mathrm{~J} / \mathrm{cm}^{3}$ at a density of 0.35 $\mathrm{g} / \mathrm{cm}^{3}$. Beyond this point, the energy absorption falls with increasing density. This behavior is unlike that observed for the quasi-static compression testing. In that case, energy increased monotonically with density over the entire range of foam densities examined (see Figure 11) with no maximum, such as that shown in Figure 15, observed. The impact data therefore identifies an 
intrinsic limitation of the material that is not evident in conventional compression testing and suggests that there is an optimum foam density above which energy absorption is degraded. These differences emphasize the importance of performing tests under conditions that simulate, as closely as possible, the actual loading conditions that are likely to be experienced by encapsulants in their intended service environments.

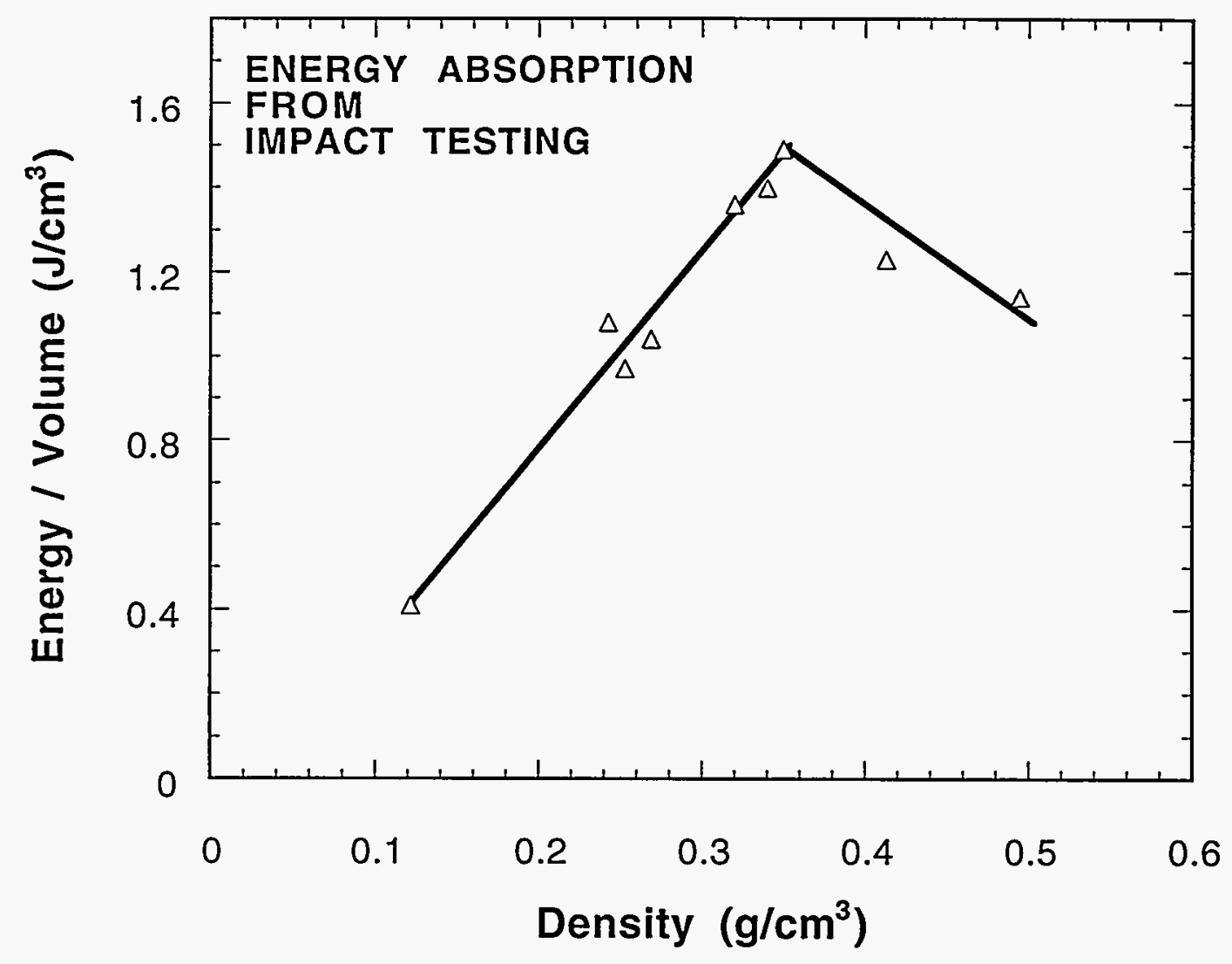

Figure 15. Energy absorption of CRETE vs. density for impact testing. Unlike quasi-static testing, energy absorption peaks at an intermediate value of density. 


\section{Relationship Between the Structure of Foams and Mechanics of Deflection}

The density dependence of both the modulus and the elastic collapse stress of a cellular foam can be understood in terms of the mechanical properties of the polymer material from which the cell struts (and in the present case, the cell walls) are made and the deformation mechanics of the cellular structure itself. Elastic moduli are related principally to the bending stiffness of the members comprising the cellular structure while the elastic collapse is caused by the elastic buckling of these same members.

For the discussion presented below, the important cell strut/wall properties are the solid polymer density, $\rho_{s}$, and its modulus, $E_{s}$. The important structural features for the analysis of the modulus and the collapse stress are the relative density of the foam, $\rho^{\star} / \rho_{s}$, (as before, $\rho^{*}$ is the density of the foam) and whether or not the cells are open or closed. In this regard a parameter, $\phi$, is defined as the fraction of material in the cell struts. For an open cell foam, $\phi=1$, while for a closed cell foam, where some of the polymer is in the cell walls, it is less than 1 .

\section{Modulus}

Much work has been done over the last thirty years to relate the mechanical response of foams to the mechanics of cell deformation. Gibson and Ashby (3) have done an extensive review of this earlier work and have shown that, in many cases, attempts to describe the mechanical properties of cellular solids analytically have been based on incorrect assumptions. For example, the axial extension of cell walls has been used to describe the elastic behavior of foams even though the bending stiffness is the principal controlling factor. $(4,5)$ Others describe the elastic behavior of foams in a manner that requires that the cell walls of the foam be initially bent, leading to results that do not have general applicability. $(6,7)$

The principal mechanism of linear-elastic deformation for foams was first identified correctly by Menges and Knipschild as cell wall bending.(8) They also pointed out that open and closed cell foams have similar stiffness because it is the cell wall edges or struts, rather than the thin cell wall membranes, that carry the majority of an imposed load. Ko also identified cell wall bending as the controlling factor in the determination of the modulus but the model presented in that work is complicated by the extremely complex cell geometry.(9) Similarly, Patel and Finnie report in great detail the geometrical requirements necessary for various three dimensional structures to fill space.(10) Their work is predicated on the fact that as a foam expands, the bubbles or spheres which comprise it impinge to form polyhedra. They describe how no regular polyhedra can meet all of the angular requirements for mutually shared edges while satisfying compatibility (that is, that the repeated polyhedron fills all space with no void). The only structure that meets all geometric requirements is the "minimum area tetrakaidecahedron" having 109.47 degree angles between adjoining pairs of cell edges and having hexagonal faces of double curvature. Analysis of the mechanics of a cell structure based on such a unit cell leads to intractable mathematics. The authors attempt to simplify their analysis by using a pentagonal dodecahedron which approximately satisfies the geometry and compatibility requirements. However, even this simplification leads to an extremely complex analysis that is difficult to apply generally.

A much simplified model of an open cell foam has been put forth (11) in which the foam is modeled as an array of cubic cells of length, $\ell$, and struts of thickness, $t$, as shown in Figure 16. 
The cells are then staggered so that corners of one cell rest upon the midpoint of adjacent cells. Such a structure neither corresponds to the actual geometric characteristics of a real foam nor can be reproduced to fill space. This "unit cell" does, however, capture the critical physical processes that govern the deformation and structural stability of a cellular structure. Defined in this manner, the volume of material in each strut is :

$$
V_{\text {strut }}=t^{2} \ell
$$

Since each strut is shared by a maximum of three adjoining cells, the relative volume of material in each cell is:

$$
V^{*} \geq \frac{12}{3} t^{2} \ell
$$

The relative density of such a foam structure is related to the cell dimensions as:

where $V_{c}$ is the cell volume, $\ell^{3}$.

$$
\frac{\rho^{*}}{\rho_{S}} \propto \frac{V^{*}}{V_{c}} \propto\left(\frac{t}{\ell}\right)^{2}
$$

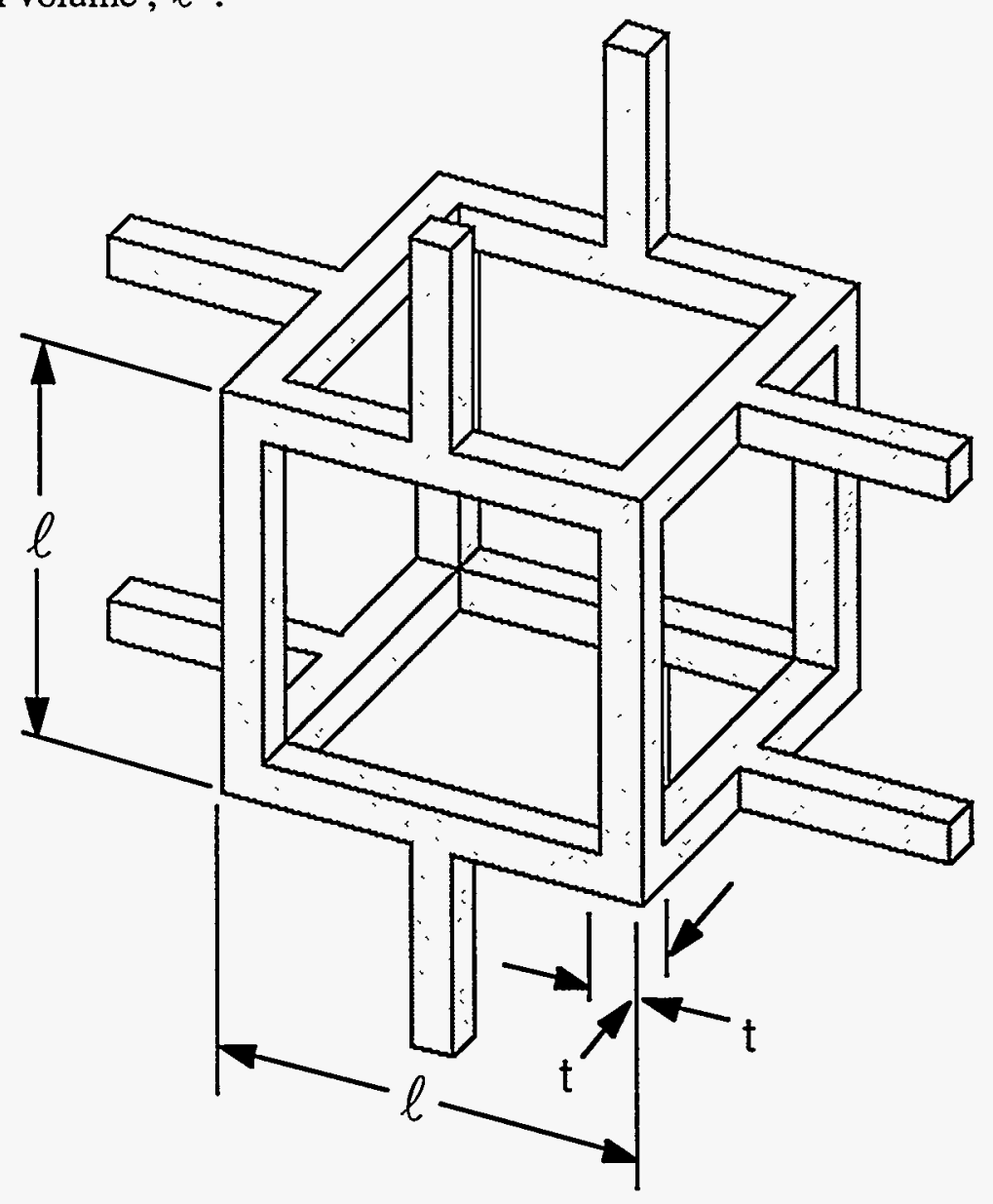

Figure 16. Unit cell for an open cell foam of cubic symmetry. The cell is comprised of edges or struts of length, $\ell$, and thickness, $t$. 
The elastic modulus of the cellular structure can be calculated from the elastic deflection of a beam of length $\ell$ loaded at its mid-point by a load, $F$, as shown in Figure 17. Beam theory (12) gives this deflection, $\delta$, as:

$$
\delta \propto \frac{F \ell^{3}}{E_{s} I}
$$

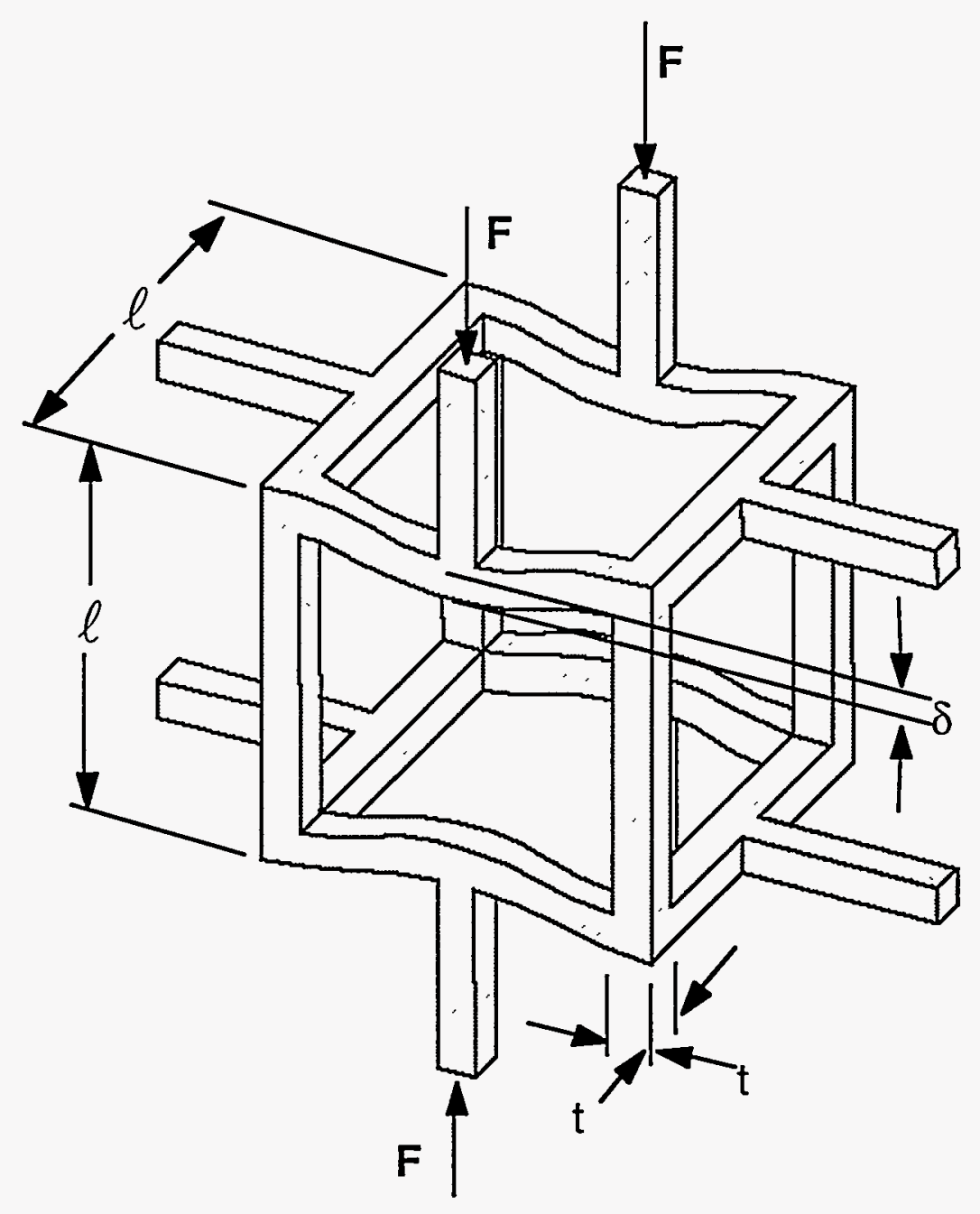

Figure 17. Unit cell shown after linear-elastic deflection of magnitude, $\delta$, induced by a force, $F$.

where, $I \propto t^{4}$, is the moment of inertia of the point loaded strut. When a uniaxial remote stress is applied to the foam so that each strut sees a transmitted force equal to $F$, the entire structure then suffers an elastic deflection given by Equation 5 . The remote stress, $\sigma$, is proportional to $F / \ell^{2}$ and the overall strain, $\varepsilon$, scales with the cell dimensions as $\delta / \ell$. The modulus of the foam therefore is given as:

$$
E^{*}=\frac{\sigma}{\varepsilon}=\frac{C_{1} E_{S} I}{\ell^{4}}
$$


where $\mathrm{C}_{1}$ contains all of the geometric constants. Since a foam is not comprised of a completely uniform cell geometry and size, it is more appropriate to determine the value of $\mathrm{C}_{1}$ by fitting Equation 6 to data rather than solving for it analytically. Gibson and Ashby $(3,11)$ have fit Equation 6 to modulus measurements for a wide range of materials and have shown that $C_{1} \approx 1$. Using Equation 4 and substituting for l:

$$
\frac{E^{*}}{E_{S}} \approx\left(\frac{t^{4}}{\ell^{4}}\right) \approx\left(\frac{\rho^{*}}{\rho_{s}}\right)^{2}
$$

Equation 7 describes the density dependence of the elastic modulus of an open cell foam only at small displacements. As strains increase and the loading on the struts parallel to the applied force approaches the Euler load, buckling occurs. Under these conditions deflection is no longer linear with increasing stress and Equation 7 no longer applies. However, at low strains where the additional moments induced by Euler buckling can be ignored, Equation 7 is valid and is applicable to tensile loading as well.

Equation 7 predicts that, at low strains, a parabolic relationship exists between the modulus of the foam and its density. The data in Figure 9 however, suggests that the power-law exponent is less than 2. This discrepancy can be found in the fact that the polyurethane CRETE is a closed cell foam rather than an open cell foam. In deriving Equation 7, it is assumed that all of the material of the foam is found in the struts that define the cells. In a closed cell foam, some fraction of the polymer resides in the cell walls or faces rather than in the struts, see Figure 18.

If the fraction of polymer contained in the cell struts having thickness $t$ is $\phi$, then the fraction contained in the cell walls of thickness $t_{f}$ is $(1-\phi)$. The stiffness of a closed cell foam results then from three contributions. The first component is strut bending, as for open cell foams. The second component is membrane (cell face) stretching $(10,12)$ which arises as the result of strut flexure causing the cell walls to deform. The final component is internal gas pressure of the closed cells.

Gibson and Ashby $(3,11)$ derive the modulus of a closed cell foam which accounts for all three components:

$$
\frac{E^{*}}{E_{S}} \approx \phi^{2}\left(\frac{\rho^{*}}{\rho_{s}}\right)^{2}+(1-\phi) \frac{\rho^{*}}{\rho_{s}}+\frac{p_{o}\left(1-2 v^{*}\right)}{E_{s}\left(1-\rho^{*} / \rho_{s}\right)}
$$

The first term on the right describes the contribution of the cell struts to the modulus while the second term accounts for the cell walls. The third term is the contribution due to internal gas pressure where $v^{*}$ is Poisson's ratio for the foam. When $p_{0}$ is small, gas pressure effects are negligible, as is the current situation. Equation 8 then reduces to:

$$
\frac{E^{*}}{E_{s}} \approx \phi^{2}\left(\frac{\rho^{*}}{\rho_{s}}\right)^{2}+(1-\phi) \frac{\rho^{*}}{\rho_{s}}
$$




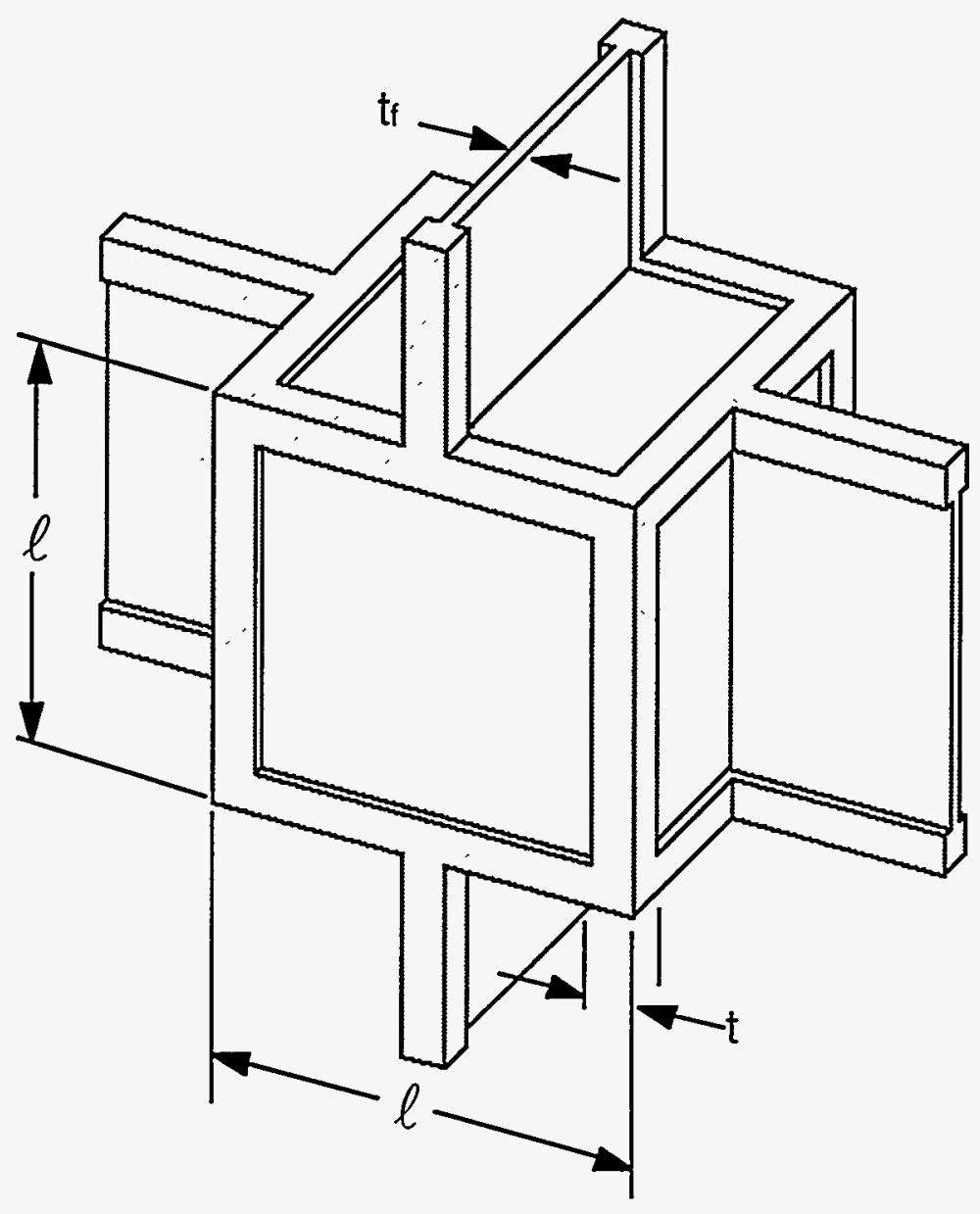

Figure 18. Unit cell for a closed cell foam of cubic symmetry. The cell is comprised of edges or struts of length, $\ell$, and thickness, t. Cell faces are enclosed by membranes of thickness $t_{\mathrm{f}}$.

Note that Equation 9 reduces to Equation 7 for $\phi=1$ (an open cell foam). The form of Equation 9 is such that at high relative densities, the modulus varies as the square of the density while at low relative densities the modulus is more nearly linearly dependent on the density. Within these density extremes, Equation 9 yields a power-law relationship which can describe the functional dependence of modulus on density with an exponent of 1.6, the value that best fits the data shown in Figure 9.

The data shown in Figure 9 can be directly compared to Equation 9 using known values for $\rho_{s}$ and $E_{s}$. This comparison is shown in Figure 19 for $\phi=0.9$. (Note: We have not independently measured $\phi$ for this foam system, the value used, $\phi=0.9$, is typical for polyurethane foams.[14]) For the density of the solid we use a value of $1.2 \mathrm{~g} / \mathrm{cm}^{3} .(15)$ The value for the modulus of solid polyurethane is less well established and varies considerably depending on the precise formulation, processing conditions and product form. Data in the literature suggest that a reasonable range for the modulus of the solid is If the fraction of polymer contained in the cell struts having thickness $t$ is $\phi$, then the fraction contained in the cell walls of thickness $t_{f}$ is $(1-\phi)$. The stiffness of a closed 
cell foam results then from three contributions. The first component is strut bending, as for open cell foams. The second component is membrane (cell face) stretching $(10,12)$ which arises as the result of strut flexure causing the cell walls to deform. The final component is internal gas pressure of the closed cells.

\section{Elastic Collapse}

The dependence of the plateau stress on foam density can be examined in a similar fashion. When a cellular solid is loaded in compression, the cell walls first flex, as shown in Figure 17. When the vertical load in Figure 17 is small, the compressed columns that comprise the cell struts parallel to the applied load are laterally stable. Indeed, small transverse displacements tend to self correct and the column returns to a position aligned with the loading direction. As the load is increased, the column becomes unstable and lateral displacements tend to remain. This instability is termed "lateral buckling" and the applied load necessary to cause it is called the "Euler buckling load". The derivation of the Euler buckling load is a well known problem in mechanics (17) and for a slender column of constant cross-section, pinned at each end and subjected to axial compression, it is given by :

$$
F_{\text {crit }}=\frac{\pi^{2} E_{s} I}{\ell^{2}}
$$

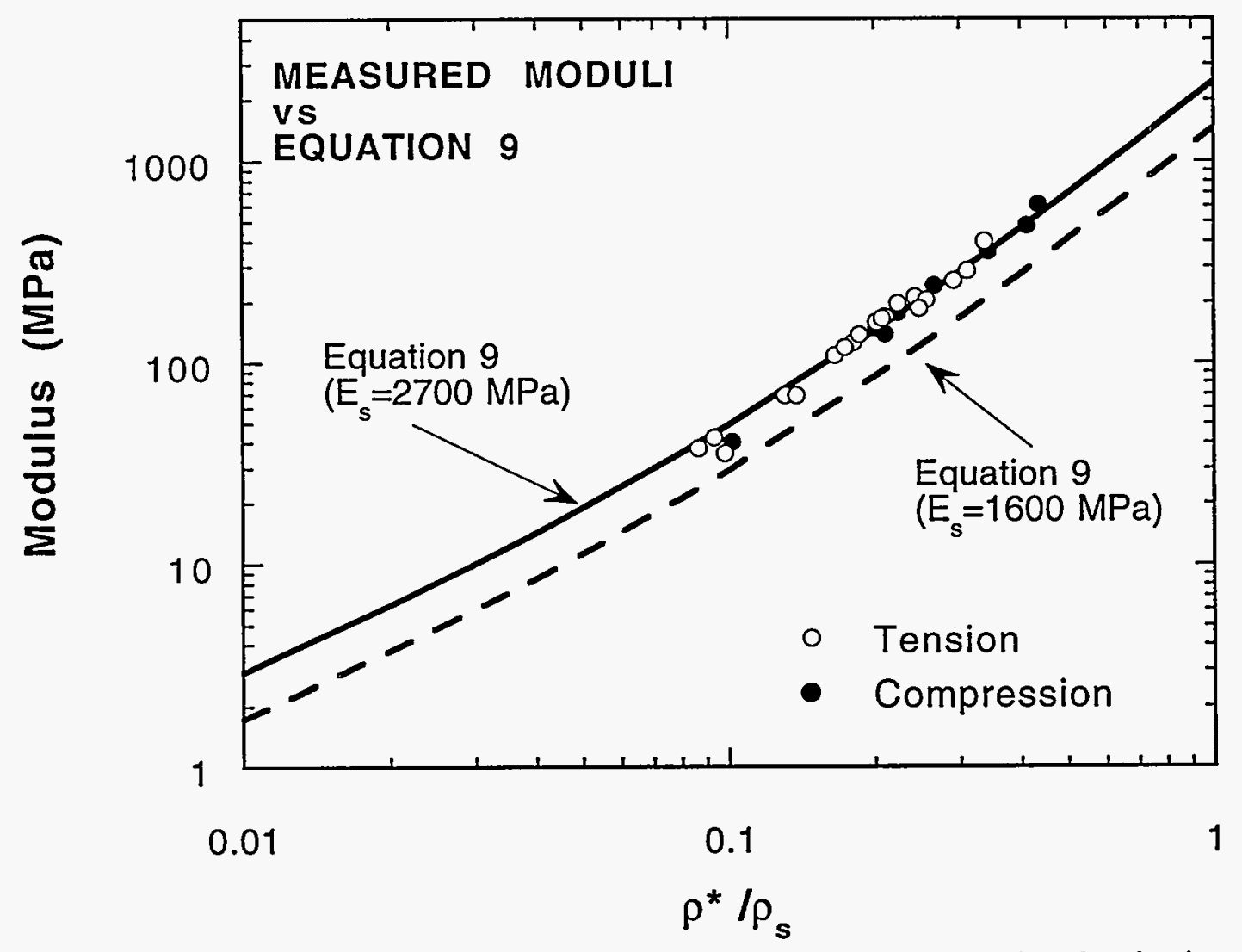

Figure 19. Comparison of modulus measurements to Eq. 9. Note that density is normalized to the density of the solid polymer. 
When this load is reached, a layer of cells in a compression specimen will buckle, initiating elastic collapse. The stress at which this happens, $\sigma_{\text {el, }}^{*}$ is given by:

$$
\sigma_{\mathrm{el}}^{*} \propto \frac{F_{\text {crit }}}{\ell^{2}} \propto \frac{E_{s} I}{\ell^{4}}
$$

Using previously defined relationships, the elastic collapse stress for cellular foam is defined as :

$$
\frac{\sigma_{\mathrm{el}}^{*}}{E_{s}}=C_{2}\left(\frac{\rho^{*}}{\rho_{s}}\right)^{2}
$$

where $\mathrm{C}_{2}$ again contains all of the proportionality constants. Note that the cell walls in a closed cell foam contribute little to buckling resistance so that no modifications to Equation 12 are necessary.

However, the densification of the material does affect the buckling characteristics. Gibson and Ashby (11) have refined Equation 12 to account for density effects and report slightly modified results (ignoring internal gas pressure):

$$
\frac{\sigma_{\mathrm{el}}^{*}}{E_{\mathrm{s}}}=C_{2}^{\prime}\left(\frac{\rho^{*}}{\rho_{\mathrm{s}}}\right)^{2}\left(1+\left(\frac{\rho^{*}}{\rho_{\mathrm{s}}}\right)^{1 / 2}\right)^{2}
$$

The correction for density is negligible when $\rho^{\star} / \rho_{s}$ is less than 0.3 , but has the effect of making the foam more resistant to collapse at higher density. In order to obtain a quantitative comparison to the data shown in Figure 10, the value of $\mathrm{C}_{2}$ must be determined. By fitting Equation 13 to data in the literature for polyurethane, polyethylene and latex rubber, Gibson and Ashby $(3,11)$ have determined that $C_{2}=0.03$. We use this independently determined value for $C_{2}$ and the same values for $\rho_{\mathrm{s}}$ and $\mathrm{E}_{\mathrm{s}}$, as used before, to compare the elastic collapse stress measurements in Figure 10 to Equation 13. The results are shown in Figure 20.

Not withstanding the uncertainty in some of the parameters, the agreement between the measured and predicted elastic collapse stress is quite good. Equation 13 predicts both the density dependence of $\sigma_{\mathrm{el}}^{*}$ as well as quantitatively predicting the actual measured values.

\section{Energy Absorption}

Toughness is essentially the product of both strength and ductility as describe in the Experimental Section. Thus, in order to effectively predict the energy absorption of foams, it is necessary to develop a model that relates the strength of the foam to the mechanics of deflection (as presented above for both modulus and elastic collapse stress) and also relates the failure strain of the foam to the intrinsic ductility of the polymer material and/or to the foam structure. With respect to the latter consideration, no such model currently exists. Such an effort is made difficult by the fact that, for many polymeric foam systems, certain properties of the bulk polymer such as ductility may not be comparable to the properties of the polymer as it exists in the cell walls of a cellular structure. 
Difference arise from a variety of factors including the fact that the blowing action that occurs during the processing of a foam induces strain and directionality on the cell struts neither of which will exist in a monolithic bulk polymer.

Other difficulties arise when trying to reproduce the bulk polymer itself. In the present case, water is the blowing agent but it also participates in the chemistry of the polyurethane reaction. Removing it from the formulation will result in a polymer of fundamentally different chemistry and structure. Another difficulty arises with respect to the heat generated by the reaction of the polyol and isocynate. The isocynate tends to boil and form pores within the "solid" polymer even if water is removed from the formulation. Such pores, acting as stress concentrators can significantly reduce the ductility of the polymer. This pore formation can be suppressed by removing the surfactant in the formulation but this further alters the chemistry of the polymer, yielding a material who's relationship to the polyurethane in the foam is uncertain.

Not withstanding these difficulties, attempts to characterize the intrinsic properties of the polymer constituents of foams and the development of models relating strength and ductility to toughness should be considered fruitful areas of research.

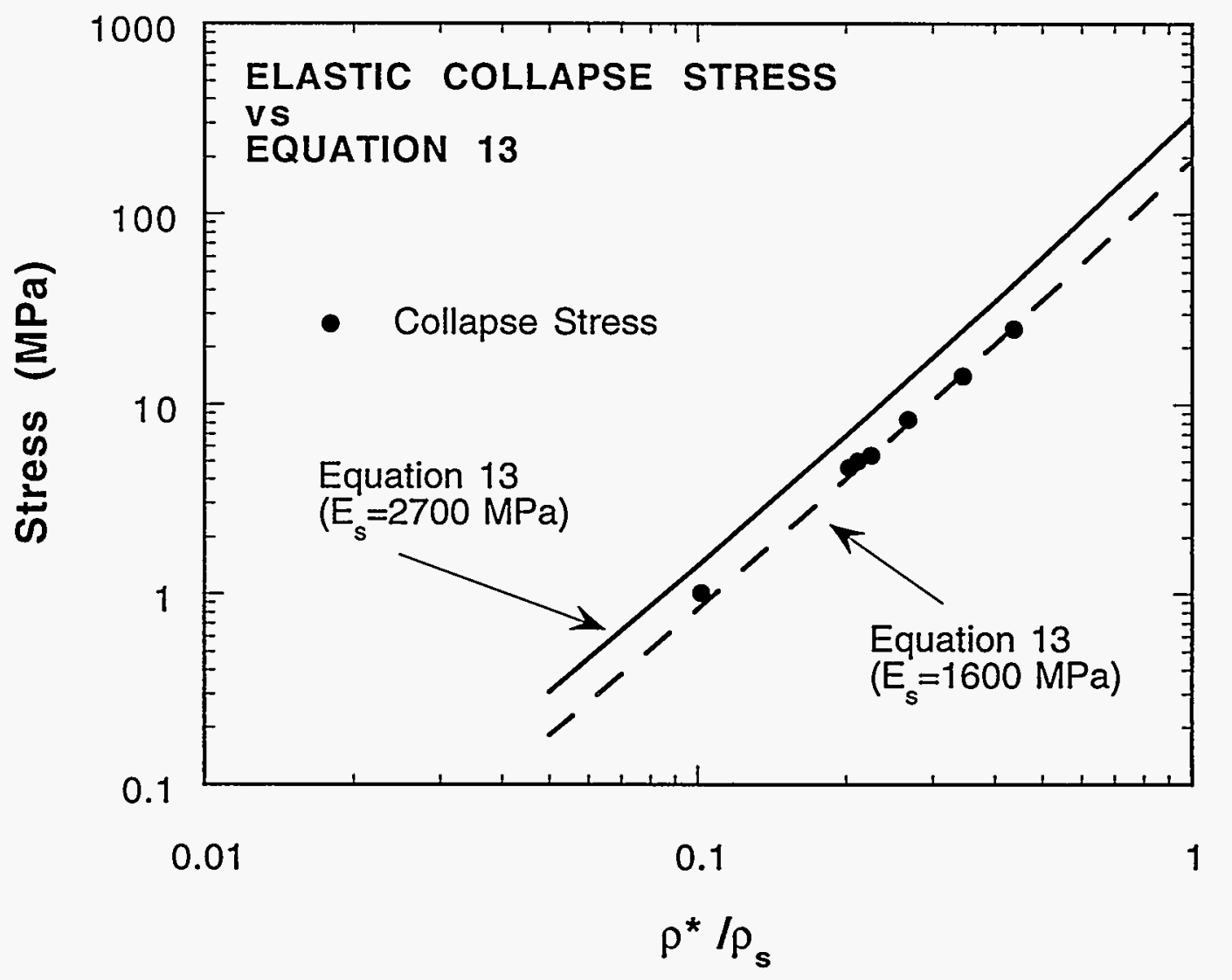

Figure 20. Comparison between the measured elastic collapse stress and Equation 13. 


\section{Conclusions}

\section{Energy Absorption Characteristics of the Foam System}

The data presented in the Results and Discussion section clearly indicate that the toughness or energy absorption characteristics of the foam are dependent on the test methods employed. The susceptibility of these foams to tensile failure results in the lowest computed values of toughness of any of the measurement schemes examined in this study. We conclude, therefore, that because these foams are inherently brittle, the use of tensile testing to characterize their shock mitigation qualities is inappropriate as it yields the least representative values for energy absorption.

Compression testing, while somewhat more realistic in terms of loading characteristics, does not capture the intrinsic limitations in the material under dynamic loading. High density specimens can be deformed to engineering strains of $>50 \%$. Low density specimens (11) can de deformed in excess of $80 \%$ without any macroscopic indication of mechanical failure. As such, the energy values determined from compression testing must be determined at some arbitrarily defined reference strain and are therefore not indicative of intrinsic material performance.

We believe that the impact test protocols established in this study yield the most realistic assessment of the energy absorption characteristics of the foam, principally due to the much higher strain rates imparted to the test specimens. Unlike conventional compression testing, impact testing revealed limitations in the shock mitigation properties. Under impact conditions, absorption energy increased monotonically as a function of density up to a maximum value of $\approx 1.4 \mathrm{~J} / \mathrm{cm}^{3}$ at a density of $0.35 \mathrm{~g} / \mathrm{cm}^{3}$. Beyond this point, the energy absorption fell with increasing density. No such maximum was observed in the quasi-static testing. In that case, energy increased monotonically with density over the entire range of foam densities examined.

\section{Structure Dependence of Modulus and Collapse Stress}

The agreement between the measured modulus and the collapse stress with those predicted by Equations 9 and 13 suggests that a model available in the literature and based on a simple, idealized cell geometry can be useful in describing certain important mechanical and physical properties of encapsulant foams. The agreement is remarkable in light of the straightforward cubic unit cell geometry chosen as the basis of the model. While not physically realistic, this cell geometry captures the density dependence of cell edge bending upon which the modulus is dependent and cell edge buckling upon which the elastic collapse stress of the foam is dependent.

Other foam systems will be examined to see if the results of the modeling described here can be useful as a general predictive tool for polymeric encapsulant materials. 


\section{References}

1. T. E. Neet, PDO 705898, Allied Signal Federal Manufacturing and Technologies, Kansas City, MO, (September 1994).

2. C. Henderson, SAND to be published.

3. L. J. Gibson and M. F. Ashby, Proc. Roy. Soc., A382:43 (1982).

4. A. N. Gent and A. G. Thomas, J. Appl. Polymer Sci, 1:107 (1959).

5. J. M. Lederman, J. Appl. Polymer Sci., 15:693 (1971).

6. R. Chan and M. Nakamura, J. Cell. Plastics, 5:112 (1969).

7. P. Barma, M. B. Rhodes and R. Salovey, J. Appl. Physics, 49:4985 (1978).

8. G. Menges and F. Knipschild, Polymer Engr'ing Science, 15:623 (1975).

9. W. L. Ko, J. Cell Plastics, 1:45 (1965).

10. M. R. Patel and I. Finnie, J. Mater., 5:909 (1970).

11. L. J. Gibson and M. F. Ashby, Cellular Solids, Structure and Properties (Pergamon Press, N.Y., 1988).

12. S. Timeshenko and D. H. Young, Elements of Strength of Materials, 4th Ed. (D. van Nostrand \& Co. Inc., N.Y., N.Y., 1962).

13. D. J. Green, J. Amer. Ceram. Soc., 68:403 (1985).

14. D. W. Reitz, M. A. Schuetz and L. R. Glicksman, J. Cell. Plast., 20:104 (1984).

15. W. F. Roff and J. R. Scott, Fibres, Films, Plastics and Rubbers-A Handbook of Common Polymers, (Butterworths, London, 1971), pp. 455.

16. PLASTICS DIGEST, 2:1301-1304, Pub. D.A.T.A. Business Publishing.

17. W.A. Nash, Strength of Materials, 3rd Ed. (Schaums Outline Series, McGraw-Hill, Inc., N.Y., 1994) 
UNLIMITED RELEASE

\section{INITIAL DISTRIBUTION}

Allied Signal Inc.

Federal Manufacturing \& Technologies

Division (FM\&T)

Attn: E. Grotheer, D/MB3 2C43

P. O. Box 419159

Kansas City, MO 64106159

Allied Signal Inc.

Federal Manufacturing \& Technologies

Division (FM\&T)

Attn: Dave Spieker, D/MB3 2C43

P. O. Box 419159

Kansas City, MO 64106159

AWE

Attn: Dr. N. R. Godfrey

Materials Research Division

Aldermaston Reading Berks

RG7 4PR

United Kingdom

Cambridge University

Attn: Prof. M. F. Ashby

Engineering Department

Trumpington St.

Cambridge CB2 1PZ

United Kingdom

ERG Inc.

Attn: Mr. B. D. Ledya

900 Stanford Ave.

Oakland, CA 94608

Los Alamos National Laboratory

Attn: J. Coons, ESA-WMM, MS C930

TA-16 Bldg. 200 Room 119

P. O. Box 1663

Los Alamos, NM 87545
Los Alamos National Laboratory

Attn: J. Coons, ESA-WMM, MS C930

TA-16 Bldg. 200 Room 124

P. O. Box 1663

Los Alamos, NM 87545

Stanford University

Attn: Prof. W. D. Nix

Dept. of Materials Science and Engr.

Bldg. 550

Stanford, CA 94305

L-322 James D. Lemay

MS $0328 \mathrm{~J}$. Wilder, 2674

MS 0328 M. J. Stevenson, 2674

MS 0367 P. B. Rand, 1815

MS 0613 D. B. Hardy, 1521

MS 0613 D. E. Mitchell, 1521

MS 0613 D. E. Weigand, 1521

MS 0717 W. McMurtry, 6642

MS 0958 C. Adkins, 1472

MS 0958 M. W. Donnelly, 1472

MS 0961 J. A. Sayre, 1403

MS 1411 M. Cieslak, 1831

MS 1434 G. Pike, 1802

MS 1435 H. J. Saxton, 1800

MS 9001 T. O Hunter, 8000

Attn: J. B. Wright, 2200

M. E. John, 8100

W. J. McLean, 8300

R. C. Wayne, 8400

P. N. Smith, 8500

P. E. Brewer, 8800

D. L. Crawford, 8900

MS 9042 D. B. Dawson, 8746

MS 9042 W. Y. Lu, 8746

MS 9042 W. A. Kawahara, 8746

MS 9403 M. I. Baskes, 8712

MS 9403 S. H. Goods, 8712 (10)

MS 9403 B. C. Odegard, Jr., 8712 
MS 9403 J. E. Smugeresky 8712

MS 9403 M. Tootle, 8712

MS 9405 D. L. Lindner, 1809

MS 9405 M. T. Dyer, 8700

Attn: M. W. Perra, 8711

J. C. F. Wang, 8713

G. J. Thomas, 8715

K. L. Wilson, 8716

W. G. Wolfer, 8717

G. A. Benedetti, 8741

L. I. Weingarten (A), 8742

P. E. Nielan, 8743

W. A. Kawahara, 8746

MS 9405 L. A. Domeier, 8230

MS 9405 C. C. Henderson, 8230 (5)

MS 9405 J. M. Hruby, 8230

MS 9405 P. N. Keifer, 8230

MS 9405 C. L. Neuschwanger (5)

MS 9405 D. M. Skala, 8230 (5)

MS 9405 L. L. Whinnery, 8230

MS9420 L. A. West, 8200

Attn: L. N. Tallerico, 8204

B. E. Affeldt, 8210

V. C. Barr, $8210-1$

M. H. Rogers, 8220

A. J. West, 8240

J. A. Fordham, 8240-1

R. H. Stulen, 8250

MS 9021 Technical Communications Department for OSTI (10)

MS 9021 Technical Communications Department, 8815/Technical Library, MS0899, 4414

MS 0899 Technical Library, 4414 (4)

MS 9018 Central Technical Files, 8940-2 (3) 